\title{
Endocytosis in the adaptation to cellular stress
}

\author{
Tania López-Hernández ${ }^{1, *}$, Volker Haucke ${ }^{1,2, *}$ and Tanja Maritzen ${ }^{1, *}$ \\ ${ }^{1}$ Leibniz-Forschungsinstitut für Molekulare Pharmakologie (FMP), 13125 Berlin, Germany. \\ ${ }^{2}$ Freie Universität Berlin, Faculty of Biology, Chemistry, Pharmacy, 14195 Berlin, Germany. \\ * Corresponding Authors: \\ Tania López-Hernández, Leibniz-Forschungsinstitut für Molekulare Pharmakologie (FMP), 13125 Berlin, Germany; \\ E-mail: lopezhernandez@fmp-berlin.de \\ Volker Haucke, Leibniz-Forschungsinstitut für Molekulare Pharmakologie (FMP), 13125 Berlin, Germany; \\ E-mail: haucke@fmp-berlin.de; \\ Tanja Maritzen, Leibniz-Forschungsinstitut für Molekulare Pharmakologie (FMP), 13125 Berlin, Germany \\ E-mail: maritzen@fmp-berlin.de
}

ABSTRACT Cellular life is challenged by a multitude of stress conditions, triggered for example by alterations in osmolarity, oxygen or nutrient supply. Hence, cells have developed sophisticated stress responses to cope with these challenges. Some of these stress programs such as the heat shock response are understood in great detail, while other aspects remain largely elusive including potential stress-dependent adaptations of the plasma membrane proteome. The plasma membrane is not only the first point of encounter for many types of environmental stress, but given the diversity of receptor proteins and their associated molecules also represents the site at which many cellular signal cascades originate. Since these signaling pathways affect virtually all aspects of cellular life, changes in the plasma membrane proteome appear ideally suited to contribute to the cellular adaptation to stress. The most rapid means to alter the cell surface proteome in response to stress is by alterations in endocytosis. Changes in the overall endocytic flux or in the endocytic regulation of select proteins conceivably can help to counteract adverse environmental conditions. In this review we summarize recent data regarding stress-induced changes in endocytosis and discuss how these changes might contribute to the cellular adaptation to stress in different systems. Future studies will be needed to uncover the underlying mechanisms in detail and to arrive at a coherent picture. doi: $10.15698 /$ cst2020.10.232

Received originally: 26.05 .2020

in revised form: 24.07.2020,

Accepted 29.07.2020,

Published 18.08.2020.

Keywords: clathrin-mediated endocytosis; cancer; nutrient signaling; osmotic stress; mechanical stress; hypoxia; oxidative stress.
Abbreviatons:
AMPK - AMP-activated kinase,
Bsep - bile salt export pump,
CME - Clathrin-mediated endocytosis,
EGFR - epidermal growth factor
receptor,
ENaC - epithelial sodium channel,
GDI-guanyl-nucleotide dissociation inhibitor,
GPCR - G-protein coupled receptor,
HIF - Hypoxia inducible factor,
$L D L$ - low density lipoprotein,
$L D L R-L D L$ receptor,
$O G D$ - oxygen and glucose deprivation,
ROS - reactive oxygen species.

\section{INTRODUCTION}

Cells have to cope with challenging changes in their environment such as alterations in osmolarity, ion homeostasis, redox state, oxygen or nutrient supply, or exposure to ionizing radiation or potentially toxic substances. Deviations from homeostatic conditions are often unfavorable to cellular life and elicit stress responses that have evolved to foster adaptation to the altered conditions and, thereby, promote cellular survival in adverse environments. A prominent example is the heat shock response that is triggered by exposure to elevated temperatures [1]. In this case the impaired protein folding induced by heat stress is, at least partially, counteracted by an increased expression of chap- erone proteins. These assist with protein folding and thereby, help to keep the cellular protein machinery functional in spite of adverse thermal conditions. While certain aspects of stress-elicited adaptive programs such as the heat shock response or the oxidative stress response are very well studied, the contribution of other cellular pathways including endocytosis to cellular adaptation is still elusive.

The plasma membrane can be envisioned as a central compartment in the cellular adaptation to diverse stress conditions as it shapes the interactions between cells and their environment by harboring an elaborate complement of transmembrane proteins, e.g. transporters, channels, 
receptors, or adhesion proteins. These cell surface proteins impinge on the vast majority of all cellular functions by mediating nutrient uptake, preserving ion homeostasis and initiating complex signaling cascades in response to extracellular cues. Consequently, the dynamic remodeling of the cell surface proteome is likely a crucial process in the cellular adaptation to many stress conditions.

A powerful pathway for rapidly altering the protein composition of the plasma membrane is Clathrin-mediated endocytosis (CME). In CME, Clathrin together with additional endocytic factors causes the invagination of a plasma membrane patch into a $100 \mathrm{~nm}$-sized vesicle that delivers its cargo to the endosomal system [2]. This pathway was proposed to account for $\sim 95 \%$ of total protein endocytic flux [3] and, thus, is the prime candidate for modulating the surface proteome upon stress. CME is especially well suited to this task by allowing the selective uptake of specific transmembrane proteins via the recognition of distinct sorting motifs by endocytic adaptor proteins. In fact, different reports have highlighted that there is close crosstalk between endocytosis, early endosomal trafficking and cellular stress.

In this review we summarize reported stress-induced adaptive changes in the surface proteome that may be brought about by alterations in CME or downstream endocytic trafficking and discuss how these might contribute to cellular survival.

\section{MECHANISM OF CME}

CME is initiated by the recruitment of early-acting endocytic proteins, termed adaptors, such as FCHo, Eps15, Eps15R, and the Clathrin assembly protein complex 2 (AP2) as well as curvature-inducing proteins such as Epsins and CALM to the plasma membrane [2]. These adaptors link Clathrin to the underlying membrane via their association with charged plasma membrane lipids and couple the assembly of the Clathrin coat with the selection of transmembrane cargo proteins, e.g. receptors and their ligands.

Endocytic adaptors are crucial for the endocytic process as they conduct the selection of membrane proteins destined for endocytosis (i.e. cargo) [4]. For example, specific adaptors such as ARH enable liver cells to internalize low-density lipoprotein receptors (LDLRs) to clear cholesterol from the circulation. Loss of these adaptors causes hypercholesterolemia and atherosclerosis in humans [5]. Other examples include $\beta$-arrestins that sort active G-protein coupled receptors (GPCRs), Epsins, Eps15 and Eps15R that recognize ubiquitinated receptors [6], and CALM and AP180 which mediate the endocytosis of socalled SNARE proteins that are crucial for membrane fusion $[7,8]$. In addition, many internalized transmembrane proteins are recognized by the AP-2 complex, a heterotetramer of two large $(\alpha, \beta 2)$ and two small subunits $(\mu 2, \sigma 2)$, that acts as a more general cargo adaptor. AP-2 harbors specific sites for its association with dileucine- (i.e. [DE]XXXXL[LI], $X$ $=$ any amino acid) and tyrosine-based (i.e. $Y x x \emptyset, X=$ any amino acid, $\varnothing=$ large hydrophobic residue) endocytic sorting motifs [9-11] as well as for basic $\mathrm{C} 2$ domains [12]. The latter are also recognized by the $\mathrm{AP}-2 \mu$ related adaptor proteins Stonin2 [13] and SGIP1 [14].

Cargo selection is closely coordinated with the assembly of the Clathrin lattice to generate productive endocytic structures. AP-2 in this mechanism acts as a co-incidence detector by initially adopting a closed conformation in which all but one membrane binding site as well as its cargo and Clathrin binding sites are occluded $[15,16]$. This inactive conformation prevents the association of AP-2 with cargo proteins at sites other than the plasma membrane. The switch to the active open conformation is promoted by the coincident binding of AP-2 to the plasma membrane lipid phosphatidylinositol(4,5)bisphosphate $\left(\mathrm{PIP}_{2}\right)$ and the AP-2 activating domain of $\mathrm{FCHo}$ proteins [17]. In the open conformation further $\mathrm{PIP}_{2}$ binding sites are exposed, and the interaction surfaces for cargo and Clathrin become accessible. Cargo, $\mathrm{PIP}_{2}$, and Clathrin binding stabilize the open conformation. Phosphorylation of the $\mu 2$ subunit by the adaptor associated kinase 1 (AAK1) or GAK $[18,19]$ promotes the open conformation, whereas NECAPs convert the phosphorylated open conformation of AP-2 into its inactive closed form [20, 21]. Hence, AP-2 is a central target for regulation in $\mathrm{CME}$. One of the physiological triggers for AP- $2 \mu$ phosphorylation is for example dopamine. Dopamine binding to its cognate GPCR leads via the activation of AAK1 and PKC- $\zeta$ to AP- $2 \mu$ phosphorylation, thereby promoting endocytosis, e.g. of the $\mathrm{Na}^{+} / \mathrm{K}^{+}$-ATPase [22].

As cargo selection and concomitant Clathrin assembly progress, the assembled coat and the underlying membrane bend inward, into the direction of the cytoplasm, until eventually a vesicle-like structure is formed, the endocytic pit, which remains connected to the membrane only via a narrow stalk [2]. Active membrane remodeling during this transition from a flat Clathrin lattice to a deeply invaginated endocytic pit is facilitated by curvature-sensing and -inducing Bin-Amphiphysin-Rvs (BAR) domaincontaining proteins such as FCHo, Sorting Nexin 9 (SNX9), Amphiphysin, and Endophilin. Finally, the membrane stalk is fissioned by the GTP hydrolyzing mechano-chemical enzyme Dynamin [23], and the Clathrin coat is shed with the help of the chaperone Hsc70 and auxilin or GAK [24] resulting in the release of a cargo-filled vesicle into the cytoplasm. The neuronal isoform 1 of Dynamin and FCHSD2, a protein that promotes actin polymerization at the base of Clathrin-coated pits [25], were both shown to be phosphorylated as downstream targets of oncogenic signaling cascades that stimulate endocytosis $[26,27]$ making it likely that they also constitute regulatory points during stress.

During the late stages of endocytosis the forming endocytic vesicle is primed for its fusion with early endosomes via the activation of the small GTPase Rab5 at the onset of vesicle uncoating [28]. Rab5-containing endosomes act as sorting platforms for cargo delivery either to a recycling pathway or for lysosomal degradation. Consistently, loss of function of Rab5 has been shown to impair endocytosis $[28,29]$ and to inhibit early endosome fusion [30]. The balance between the delivery of newly synthesized membrane proteins, their endocytosis, recycling and 
degradation will determine the pool of membrane proteins present at the plasma membrane. Therefore, alterations in endocytosis constitute a rapid means of altering the surface levels of select proteins and identify CME as an attractive mechanism for the acute cellular adaptation to stressful environmental changes.

\section{MECHANISMS OF REGULATION OF CME UPON STRESS CONDITIONS}

Adaptive programs elicited by environmental stresses such as starvation, hypoxia, or alterations in ion strength or composition, among many other challenges, could either regulate bulk endocytic flux or alter the uptake of select proteins. Altering bulk endocytic flux would result in a nonselective increase or decrease in the endocytic uptake of various cargos. This might have general benefits, for example, energy preservation when overall endocytosis is downregulated or the restoration of membrane tension when endocytosis is upregulated. An increase in endocytosis during stress might also be beneficial to elevate nutrient intake and thereby strengthen cellular resilience (Figure 1). For example, iron, which is taken up via CME of transferrin, is an important cofactor for a range of cellular enzymes including those required for mitochondrial oxidative phos- phorylation [31]. To induce an overall change in endocytosis, key players in CME such as Clathrin, AP-2, or Dynamin may be altered in their activities or levels.

Stress-induced changes in the endocytosis of select membrane proteins on the other hand could be used to switch on or to amplify specific cellular pathways counteracting deleterious stress effects. To achieve a selective change in the endocytosis of a specific membrane protein, the first option would be to modify the protein itself to alter its affinity for the endocytic machinery. These modifications are normally posttranslational. For example, proteins can be marked for endocytosis via phosphorylation. This is the case for GPCRs that following phosphorylation by G-protein coupled receptor kinases (GRKs) bind to their specific endocytic adaptor, $\beta$-arrestin. Alternatively, cargo proteins can become ubiquitinated like the epidermal growth factor receptor (EGFR) or vascular endothelial growth factor receptor 2 (VEGFR2) for sorting by endocytic adaptors such as Eps15, Eps15R and Epsins that carry ubiquitin interaction motifs. Alternatively, modifications of specific adaptor proteins might be employed to trigger changes in the endocytosis of select cargos. For example, ARH, the endocytic adaptor that facilitates the internalization of ligand-bound LDLRs, needs to be S-nitrosylated to interact

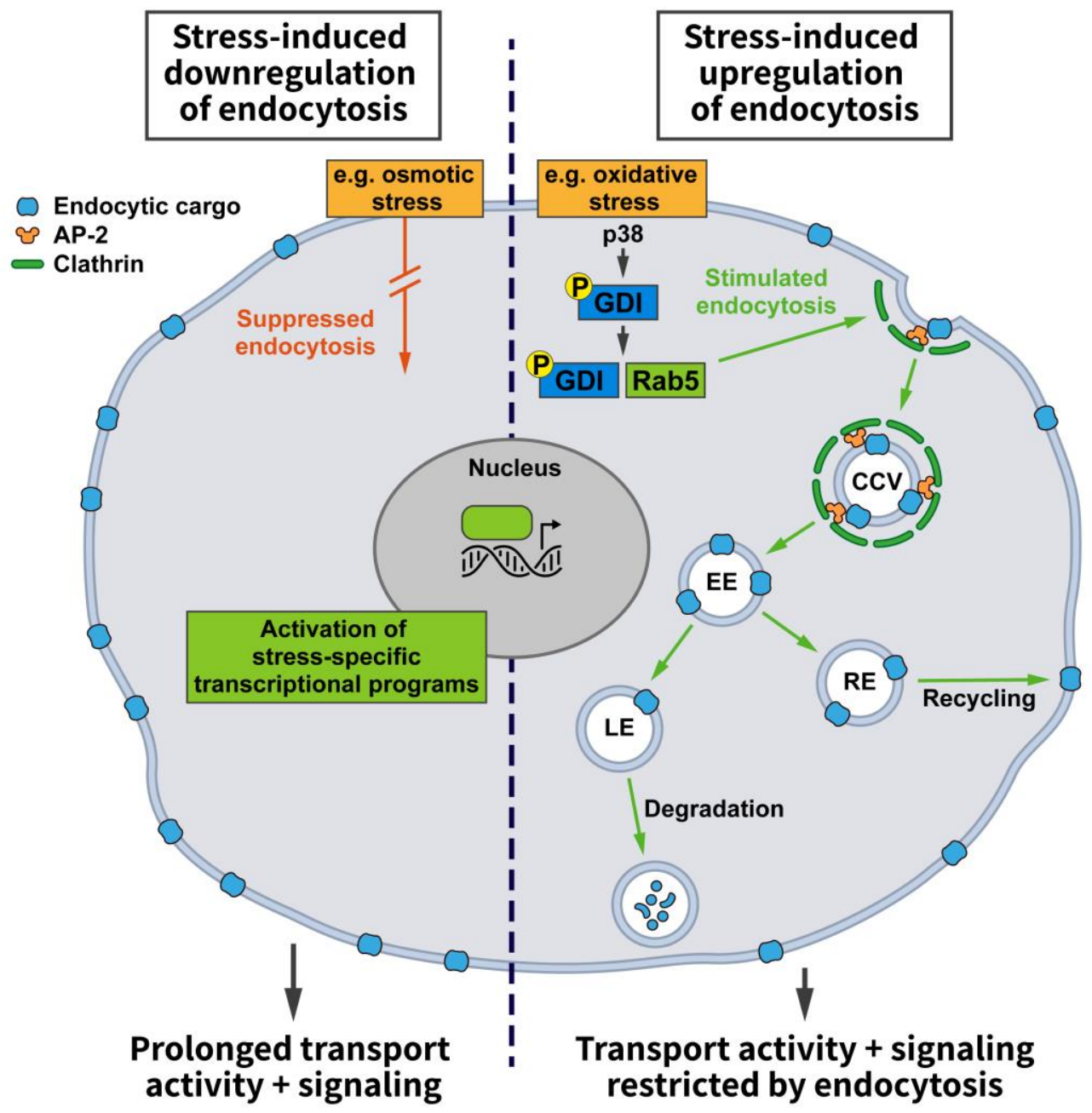

FIGURE 1: Effects of stress conditions on Clathrinmediated endocytosis. Stress conditions can either promote (right side) or hamper (left side) endocytosis. Increased endocytosis, e.g. triggered by the stress-induced activation of the mitogen-activated protein kinase p38 that activates Rab5 by promoting the formation of GDI:Rab5 complexes, reduces the cell surface levels of transmembrane cargo proteins. This may, for example, restrict signaling from the plasma membrane or the transporter-mediated uptake of nutrients and/or enhance the endocytic uptake of specific proteinbound ligands. Conversely, downregulation of endocytosis will extend the residence time of signaling receptors and transporters at the cell surface, thereby promoting their activities (see text and other figures for details). 
with AP-2 [32]. This type of modification could conceivably be modulated by cellular redox state and, thus, be responsive to certain types of stress. Since a number of kinases such as protein kinase $N(P K N)$ and the mitogen-activated protein kinase (MAPK) p38 are known to be sensitive to cellular stress conditions, such as changes in osmolarity, it is also conceivable how stress-induced signal cascades could lead to alterations in the uptake of specific proteins by introducing the phosphorylation of cargo or adaptor proteins.

In fact, the p38 pathway is one of the few stressresponsive signaling cascades that have been linked to alterations in endocytosis. Among other targets, the activation of this pathway was shown to alter the activity state of Rab5 [33], which is not only crucial for early endosomal membrane traffic, but is also known to affect endocytosis [29]. Rab5 in its cytosolic GDP-bound state is complexed to guanyl-nucleotide dissociation inhibitor (GDI), which promotes its extraction from membranes. GDI activity is stimulated by active p38, and the increase in Rab5:GDI complexes appears to promote endocytosis in line with earlier reports [28]. Even though this study only analyzed the uptake of HRP and dextrans [33], i.e. signature cargos of fluid phase endocytosis, it is likely that the findings can be extended to CME since Rab5:GDI has been proposed to act at Clathrin-coated pits [28].

Given the multitude of different environmental stresses and their potential impact on distinct cell and organ systems, it is not surprising that no systematic studies on the regulation of CME by various stress conditions have been performed and no consensus picture or mechanism has emerged yet. Moreover, in many studies, specific effects of environmental stresses on the endocytosis or plasma membrane level of a defined membrane protein have not always been discerned from effects on CME in general. Hence, it often remains unclear whether a given stress elicits a cargo-selective endocytic change or a more global effect on CME and/or associated pathways, e.g. endosomal sorting downstream of CME. We have therefore refrained from a clear distinction between these mechanisms. Instead, we provide an overview of the various reports describing a regulatory role of different stress conditions on the endocytosis of distinct membrane proteins (Table 1 ).

\section{STRESS CONDITIONS THAT AFFECT ENDOCYTOSIS}

In contrast to the molecular mechanism of CME that has been dissected in detail during the past decades, the regulation of $\mathrm{CME}$ under different physiological conditions remains poorly understood. It is generally assumed that endocytosis is a constitutive process. However, different cellular and environmental factors can influence the efficiency of endocytosis. Alternatively, as alluded to above, environmental stresses may impact on the endocytosis or plasma membrane levels of specific membrane proteins. In this chapter we will summarize what is known with respect to various types of stress conditions and their impact on endocytosis.

\section{Oncogenic signaling}

The most systematically addressed regulatory influence on CME so far is oncogenic signaling by which tumor cells "adapt" CME for their purposes [27]. By screening a panel of oncogenic signaling kinase inhibitors, the Schmid lab uncovered that ten of the 21 studied pathways affected CME [27], even though for most of them it is still unclear how they influence CME mechanistically. Concentrating on ERK1/2 signaling, Xiao et al. showed that ERK-dependent phosphorylation of FCHSD2, which acts in the maturation of Clathrin-coated pits [25], promotes FCHSD2 recruitment to the plasma membrane and, thereby, CME [27]. Thus, aberrant ERK signaling appears to be a crucial factor for the rapid $\mathrm{CME}$ observed in cancer cells. While the initial screening was based on transferrin uptake, subsequent experiments demonstrated that increased CME also leads to elevated EGFR uptake. This appears at first glance counterintuitive, given that increased receptor tyrosine kinase signaling is generally considered beneficial for oncogenesis. However, as EGFR signaling is complex and takes place at both, the plasma membrane and early endosomes, the net signaling outcome in a given type of cancer cell is hard to predict. In fact, while a number of cancer cells show ERKand FCHSD2-dependent upregulation of endocytosis, in non-small-cell lung cancer (NSCLC) loss of function of FCHSD2 has been suggested to promote cell proliferation and migration [27]. The complex effects of altered CME capacity on oncogenesis may depend on the tumor cell type as reflected by the fact that high FCHSD2 levels are correlated with increased survival in NSCLC [27], whereas elevated FCHSD2 may hamper survival in acute myeloid leukemia [34]. Thus, depending on concomitant signaling changes in cancer cells, further oncogenesis may be driven either by a down- or upregulation of endocytosis. The differential regulation of $\mathrm{CME}$ in cancer cells might also reflect the fact that pro- and anti-oncogenic signaling pathways converge onto CME factors and may differentially adapt CME to cellular needs. Analogous pathways likely exist for the adaptation of CME to other types of stress conditions.

\section{Nutrient and energy deprivation}

Endocytosis and nutrient signaling

Endocytosis provides cells with nutrients. Hence, it is plausible that control of the endocytic pathway should be sensitive to nutrient availability. However, the role of endocytosis in nutrient supply and, conversely, the regulation of endocytosis by nutrients appears to be complex. Work in yeast has revealed an elegant adaptive response by which nutrient deprivation not only activates autophagy for amino acid recycling, but also inhibits the endocytosis of specific amino acid transporters, e.g. the arginine transporter Can1, to promote amino acid uptake [35]. This mechanism is regulated by nutrient signaling via mTORC1, the arrestinlike adaptor Art1, the ubiquitin ligase Rsp5, and the kinase Nrp1 (Figure 2). At steady state, Can1 is ubiquitinated by the ubiquitin ligase Rsp5, which promotes Can1 endocytosis. The ubiquitin ligase adaptor Art1 is necessary to target Rsp5 to Can1. Art1 is a substrate for the kinase Npr1, which 
TABLE 1. Effects of different stress conditions on the endocytosis of distinct membrane proteins.

\begin{tabular}{|c|c|c|c|}
\hline STRESS & $\begin{array}{c}\text { EFFECT ON } \\
\text { ENDOCYTOSIS }\end{array}$ & CARGO & REFERENCE \\
\hline & REDUCED & Dextran, arginine transporter & [35], [120] \\
\hline $\begin{array}{c}\text { NUTRIENT } \\
\text { DEPRIVATION }\end{array}$ & ENHANCED & $\begin{array}{c}\alpha 5 \beta 1 \text { integrins, } \beta 4 \text { integrins, SNAT2, SNAT3, Ser- } \\
\text { ine Incorporator } 1 \text {, Death receptors } 4 \text {, Death re- } \\
\text { ceptors } 5\end{array}$ & [38], [121], [122] \\
\hline & REDUCED & GLUT1 & [39] \\
\hline $\begin{array}{c}\text { GLUCOSE } \\
\text { DEPRIVATION }\end{array}$ & ENHANCED & $\begin{array}{l}\text { Uracil permease, amino acid permease, GluA2, } \\
\qquad \text { GluA3, GABA } A_{A} R\end{array}$ & {$[40],[41],[42]$} \\
\hline \multirow[t]{2}{*}{ HYPERTONICITY } & REDUCED & $\begin{array}{c}{[3 \mathrm{H}] \mathrm{f}-\mathrm{NleLeuPhe},[4 \mathrm{C}] \text { sucrose, hemocyanin, dex- }} \\
\text { tran, transferrin, FM dye, aquaporin2, GLUT4, } \\
\text { NHE7 }\end{array}$ & $\begin{array}{c}{[48],[50],[51],[53-55]} \\
{[123]}\end{array}$ \\
\hline & ENHANCED & EGFR & [104], [115] \\
\hline \multirow{2}{*}{ HYPOTONICITY } & REDUCED & Dextran, transferrin, $\beta$-VLDL & {$[44-46]$} \\
\hline & ENHANCED & Dextran, IgG-latex beads, Claudin-1, Claudin-2 & [63], [64] \\
\hline SHEAR & ENHANCED & LDL, FVIII-VWF, albumin, dextran & {$[65-69],[71],[72]$} \\
\hline \multirow{2}{*}{ HYPOXIA } & REDUCED & $\mathrm{Na}^{+} / \mathrm{K}^{+}$-ATPase & [79] \\
\hline & ENHANCED & $\mathrm{Na}^{+} / \mathrm{K}^{+}$-ATPase, ENaC, GLR-1, EGFR & [77], [80], [81], [124] \\
\hline HYPERCAPNIA & ENHANCED & $\mathrm{Na}^{+} / \mathrm{K}^{+}$ATPase, $\mathrm{ENaC}$ & [82], [125] \\
\hline HYPOCAPNIA & ENHANCED & $\mathrm{Na}^{+} / \mathrm{K}^{+} \mathrm{ATPase}$ & [84] \\
\hline \multirow{2}{*}{ ROS } & REDUCED & $\begin{array}{c}\text { LDL, transferrin, EGFR, lectin receptor, GLUT4, } \\
\text { aquaporin } 4\end{array}$ & [85-93] \\
\hline & ENHANCED & $\begin{array}{l}\text { Multidrug resistance-associated protein 2, bile } \\
\text { salt export pump }\end{array}$ & [95-98] \\
\hline IRON DEFICIENCY & REDUCED & DMT1, TfR & [100], [102] \\
\hline IRON OVERLOAD & ENHANCED & DMT1 & [101] \\
\hline CISPLATIN & ENHANCED & EGFR & [104] \\
\hline HEAVY METALS & REDUCED & Dextran, albumin & [103], [104], [106], [107], \\
\hline \multirow{2}{*}{ IRRADIATION } & REDUCED & Dextran, lucifer yellow & [111], [113] \\
\hline & ENHANCED & EGFR & [114], [115] \\
\hline
\end{tabular}

phosphorylates Art1 and, thereby, causes its inactivation by limiting its plasma membrane association. Under conditions of energy sufficiency Npr1 is repressed by active mTORC1, thereby enabling Art1 to trigger the ubiquitination-dependent endocytosis of Can1. During starvation when mTORC1 activity is repressed, Npr1 becomes active, resulting in Art1 inhibition and a blockade of Can1 ubiquitination and endocytosis to promote the uptake of amino acids. This work thus suggests a mechanism whereby mTORC1 promotes the internalization of amino acid trans- porters upon high nutrient availability, whereas under starvation decreased mTORC1 activity shuts down their endocytosis [35].

Art1 belongs to a family of arrestin-related proteins [36]. Therefore, it is conceivable that the outlined mechanism might encompass even more cargo proteins via the stress-dependent regulation of additional Art proteins. It is not clear yet whether this pathway also operates in mammalian cells. However, mammalian cells express a family of arrestin-domain-containing proteins that are known to link 

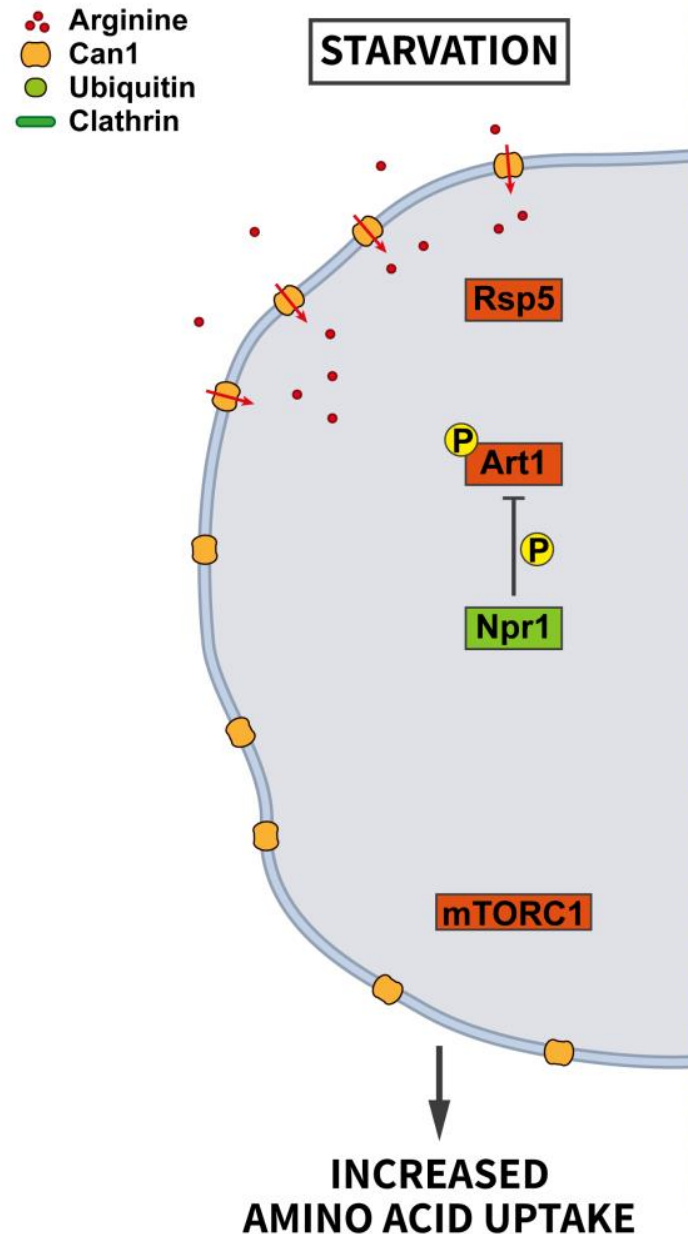

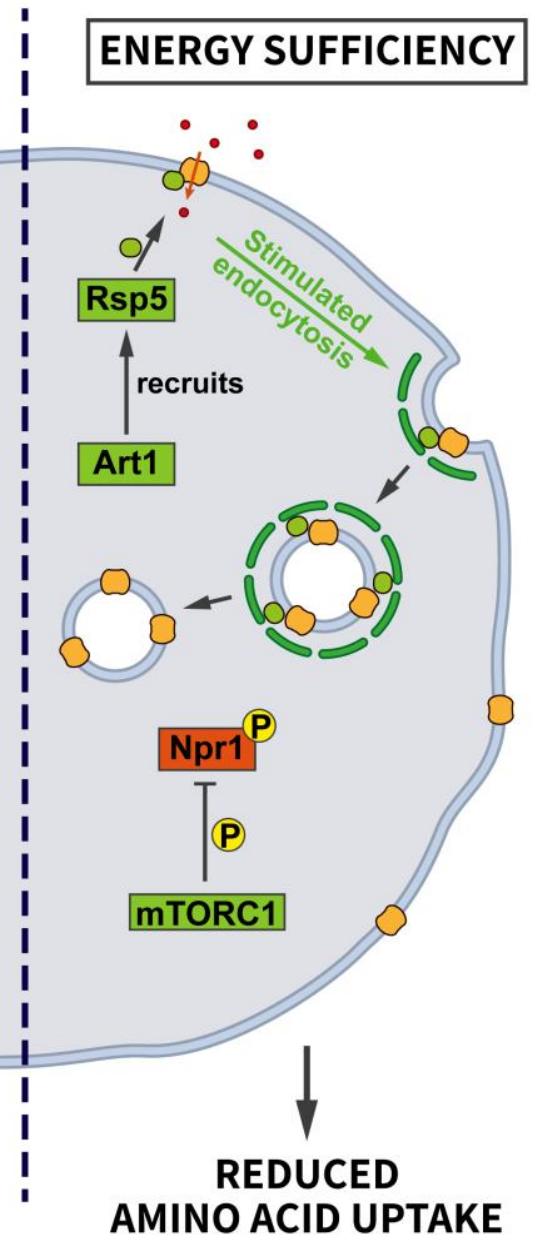

FIGURE 2: Regulation of amino acid transporter endocytosis by nutrient stress. During energy sufficiency the arrestinlike adaptor Art1 recruits the ubiquitin ligase Rsp5 to the plasma membrane to induce the ubiquitination of the arginine transporter Can1. Subsequent endocytosis of Can1 limits amino acid uptake. This pathway is regulated by the central nutrient sensor mTORC1 which in its active state keeps the negative regulator of Art1, the kinase Npr1, inactive. During starvation mTORC1 is rendered inactive so that Npr1 can inhibit Art1 via phosphorylation. Consequently, Can1 is not ubiquitinated by Rsp5 and remains at the plasma membrane to increase arginine uptake (see section "Endocytosis and nutrient signaling" for further details). CCV, clathrin-coated vesicle; $\mathrm{EE}$, early endosome; $R E$, recycling endosome; $L E$, late endosome. cargo proteins to ubiquitination. Although there is no obvious homolog of Npr1 in mammalian cells, it is interesting to note that it belongs to the same kinase family as the mammalian AMP-activated kinase (AMPK). AMPK has recently been shown to be inhibited by MTORC1 [37] and might therefore be a possible candidate for the reported mTORC1-dependent downregulation of endocytosis [35].

It is likely that the repression of Can1 internalization in nitrogen-starved yeast cells is a cargo-specific response rather than reflecting a general repression of endocytosis upon nutrient deprivation, since other studies propose that starvation rather favors endocytosis, conceivably to enhance protein degradation and, thereby, increase nutrient availability to maintain cell function. A recent study in mammalian cells combining SILAC with mass spectrometry reported that around 3\% of the proteome is degraded following starvation [38]. Many of the substrates found were plasma membrane receptors that are degraded via endocytosis and subsequent lysosomal proteolysis to protect from starvation-induced cell death.

\section{Glucose and energy deprivation}

Acute cellular energy deprivation requires adaptive changes such as increased uptake of glucose. Most cells take up glucose via the glucose transporter GLUT1, a membrane protein regulated by CME. At steady state the surface levels of GLUT1 are kept in check by the arrestin-domain containing protein TXNIP, which promotes the internalization of GLUT1. When ATP is running low and the AMP/ATP ratio increases, AMPK gets activated and phosphorylates TXNIP, thereby inducing its degradation. As a consequence, the endocytosis of GLUT1 is repressed and glucose uptake is promoted to relieve energy stress [39] (Figure 3).

Endocytosis of non-essential proteins indeed may assist survival under conditions of limited energy supply. In yeast, low glucose levels promote the endocytosis of plasma membrane proteins, such as the uracil permease Fur4 and the hydrophobic amino acid permease Tat2, to the vacuole/lysosome, while recycling to the surface is inhibited thereby promoting endocytic flux to the vacuole [40]. The mechanism that renders the recycling pathway sensitive to glucose starvation remains incompletely understood.

In the brain, impaired energy metabolism is linked to ischemia and to neurodegenerative diseases. Oxygen and glucose deprivation (OGD) invoke pathogenic processes such as increased glutamate excitotoxicity, $\mathrm{Ca}^{2+}$ overload, mitochondrial impairment, oxidative and endoplasmic reticulum stress, inflammation, and apoptosis explaining the 


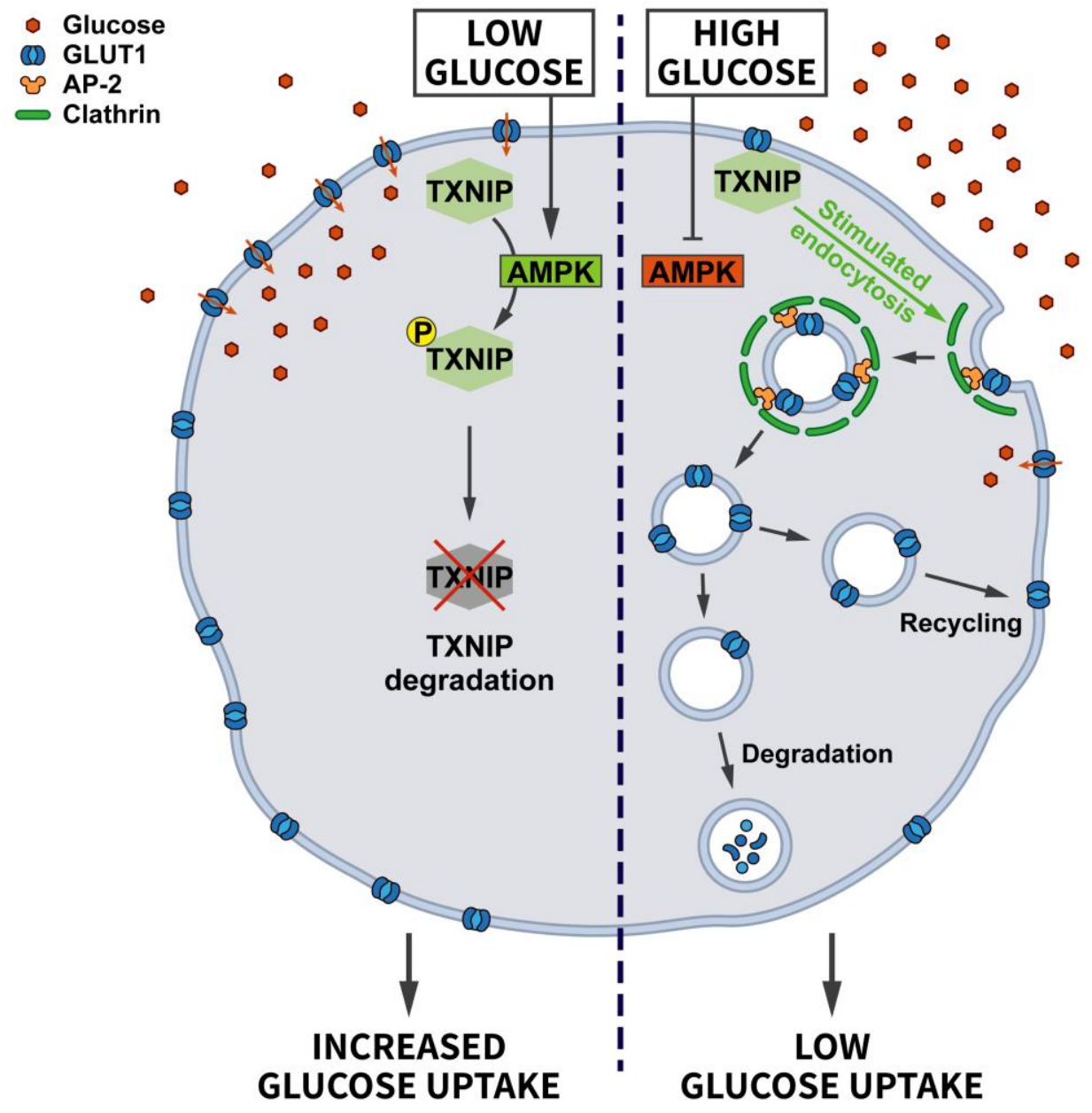

FIGURE 3: Regulation of glucose transporter endocytosis by nutrient stress. Under conditions of abundant glucose the adaptor protein TXNIP promotes the endocytosis of GLUT1 to restrict glucose uptake. When glucose levels decline, AMPK activation triggers the degradation of TXNIP, thereby downregulating GLUT1 endocytosis to promote glucose uptake (see section "Glucose and energy deprivation" for further details). ischemia-induced cerebral injury. Hypoxia inducible factors (HIFs) and the AMPK signaling pathway are known to be involved in the response to OGD. Moreover, endocytosis of the ionotropic glutamate receptors GluA2 and GluA3 in rat hippocampal neurons has been proposed to contribute to excitotoxic neuronal cell death following OGD, as more $\mathrm{Ca}^{2+}$-permeable glutamate receptors such as GluA1 homomers remain on the neuronal surface under these conditions [41]. How GluA1 endocytosis upon OGD is prevented and why endocytosis of GluA2/3 happens specifically in hippocampal, but not in cortical neurons is unclear. Likewise, AP-2 mediated-internalization of $\mathrm{GABA}_{\mathrm{A}}$ receptors from the surface of dendrites, via recognition of a specific $A P-2$ binding motif in the $G A B A_{A}$ receptor $\beta 3$ subunit, is promoted during OGD. Blocking OGD-associated $G A B A_{A}$ receptor endocytosis therapeutically to safeguard $G A B A_{A}$ receptor surface levels and, thereby, inhibitory neurotransmission would likely be beneficial for limiting OGDinduced cell death [42].

\section{Osmotic stress}

The control of osmotic homeostasis is crucial for a multitude of cellular functions. Consequently, cells have established various mechanisms for counteracting disturbances in cell volume. On the one hand, adaptive responses following osmotic swelling or shrinkage activate signaling pathways that initiate regulatory volume programs, which allow cells to recover their initial volume. On the other hand, mechanisms are triggered that help cells to cope with the impairments associated with changes in ionic strength such as protein aggregation. If swelling or shrinkage persist without adaptation, cell death is caused. Impaired volume regulation is associated with several pathologies such as ischemia/reperfusion, hypovolemia, hypernatremia and diabetic shock [43].

Hypotonic extracellular medium will cause cell swelling and an increase in membrane tension, while hypertonic conditions induce cell shrinkage and a decrease in membrane tension. Given that endocytosis in essence is a plasma membrane remodeling mechanism, conditions that alter plasma membrane tension are expected to affect the efficiency of internalization. Elevated membrane tension makes it harder to deform the membrane and, hence, hypotonic conditions oppose endocytosis. Consistently, impaired endocytosis of transferrin, $\beta$-VLDL, or dextrans under hypotonic conditions has been reported in various mammalian cell types [44-46]. Hypotonic stress can be counteracted to some degree by the actin cytoskeleton 
such that endocytosis persists even under conditions of increased membrane tension [47]. Based on these considerations, hypertonic conditions would be expected to facilitate endocytosis. However, that does not seem to be the case as demonstrated more than 40 years ago [48]. Elegant electron microscopic studies revealed that hypertonicity leads to the formation of abnormal membrane-free Clathrin microcages, thereby preventing the assembly of normal Clathrin-coated vesicles. This might be due to the fact that cell shrinkage is accompanied by cytosolic acidification, a condition known to trigger Clathrin assembly [49]. Additional factors, such as the increased concentration of proteins and divalent cations in the shrunken cells, might also contribute. Decreased receptor endocytosis upon hypertonicity has been confirmed in a variety of cell types such as polymorphonuclear leukocytes [48], Dictyostelium [50] and type I alveolar epithelial cells [51]. In addition, some studies also found fluid-phase endocytosis to be affected under osmotic shock $[50,51]$. Hence, hypo- and hypertonic stress both impair $\mathrm{CME}$.

An important trigger for plasma hyperosmolarity is elevated blood glucose (hyperglycemia). Like insulin, hyperosmolarity causes a reduction in the AP-2-dependent [52] endocytosis of GLUT4, thereby elevating its surface pool. This osmoadaptive mechanism contributes to the clearance of glucose from the blood [53]. Similarly, in epithelial renal cells aquoporin2 (AQP2) displays elevated cell surface levels upon hyperosmotic shock [54], mainly due to lower rates of AQP2 endocytosis. This adaptation will promote transcellular water flux that might be beneficial for surviving under severe hypertonic stress.

Most recently, our laboratory discovered that the differential endocytic sorting of the intracellular $\mathrm{Na}^{+} / \mathrm{H}^{+}$exchanger NHE7 is important for coping with hypertonic stress [55]. Whereas NHE7 under isotonic steady-state conditions primarily resides on endosomes and the transGolgi-network, it is redistributed to the cell surface during the early events associated with hyperosmotic shock. A similar redistribution of NHE7 is observed when CME is impaired, suggesting that NHE7 is constitutively endocytosed. The surface enrichment of NHE7 upon hyperosmotic stress is beneficial for cell survival: Plasma membrane NHE7 via downstream changes in cellular ion homeostasis and the resulting activation of the transcription factors TFEB/TFE3 promotes autophagosome and lysosome biogenesis to potentiate the degradative capacity of osmotically stressed cells. The osmotic stress-induced activation of the NHE7-TFEB pathway enables cells to cope with the increased load of aggregated proteins that accumulate during the osmotic insult and, thereby, promotes cellular survival (Figure 4). How CME of NHE7 is repressed upon hypertonic stress at the mechanistic level requires further investigations.

The NHE7-TFEB/TFE3 mechanism likely contributes to the observed induction of autophagy triggered by hypertonic stress $[56,57]$ and may synergize with the increased synthesis of phosphatidylinositol-3,5-bisphosphate, a lipid crucially required for lysosomal proteolysis, in yeast [58, 59] and mammalian cells challenged with hyperosmotic conditions [60]. These examples illustrate how alterations in endocytosis and adaptations within the autophagy/endolysosomal system downstream of endocytosis may play a key role in the intracellular anti-stress response.

Studies in yeast have added some insight into the possible mechanism underlying osmotically induced changes in endocytosis. Hypertonicity was reported to trigger alterations in intracellular $\mathrm{Ca}^{2+}$, thereby activating the $\mathrm{Ca}^{2+} /$ Calmodulin-dependent phosphatase Calcineurin. Calcineurin dephosphorylates and activates the endocytic lipid phosphatase Synaptojanin/Inp53, thereby promoting endocytosis to compensate the excess of membrane caused by hypertonicity [61]. A similar Calcineurindependent bulk endocytic response can be triggered at synapses of mammalian neurons by sustained highfrequency firing activity [62].

Interestingly, changes in tonicity have been suggested to induce endocytosis in cells of the immune system to regulate inflammatory responses. For example, hypotonic stress was reported to promote the immune function of macrophages by boosting their endocytic ability [63]. The chloride channel CIC-3 was implicated in this pathway, however, the underlying mechanism is presently unclear. In contrast, the endocytosis of claudin-1 and - 2 in epithelial tubular cells in the kidney upon osmotic stress caused by alterations in the osmolarity of the tubule fluid [64] rather represents a detrimental response, since breakdown of tight junctions and the ensuing paracellular transport accelerate renal cell injury.

\section{Mechanical Stress}

Other types of mechanical stress aside from changes in membrane tension induced by altered osmolarity have also been shown to affect endocytosis. The best example is shear stress that is experienced by cells lining vessel walls such as endothelial cells. The uptake of LDL into endothelial cells is increased under conditions of shear stress [65-68]. Interestingly, LDLR family members such as LRP1 also contribute to the shear stress-induced uptake of a complex between the coagulation factor VIII (FVIII) and its carrier protein von Willebrand factor (VWF) into macrophages [69].

In the kidney, cells sheathing the proximal tubule are highly specialized in retrieving proteins and other small molecules from the glomerular filtrate, and impaired endocytosis is known to contribute to the pathogenesis of several renal diseases. To adapt their uptake capacity to changes in glomerular filtration rate, proximal tubule cells are responsive to shear stress. In fact, the shear stress induced by the flow of the glomerular filtrate determines the extent of endocytosis on the lumenal side of proximal tubule cells [70, 71]. The important role of CME in proximal tubule-derived epithelial cells exposed to shear stress was confirmed by demonstrating that increased shear stress leads to a 2-fold increase in the Clathrin-dependent uptake of albumin and dextran via the multiligand receptors Megalin and Cubilin. This pathway involves the shear-stress induced bending of cilia that may trigger $\mathrm{Ca}^{2+}$ influx via mechanosensitive channels and $\mathrm{Ca}^{2+}$ release from the en- 


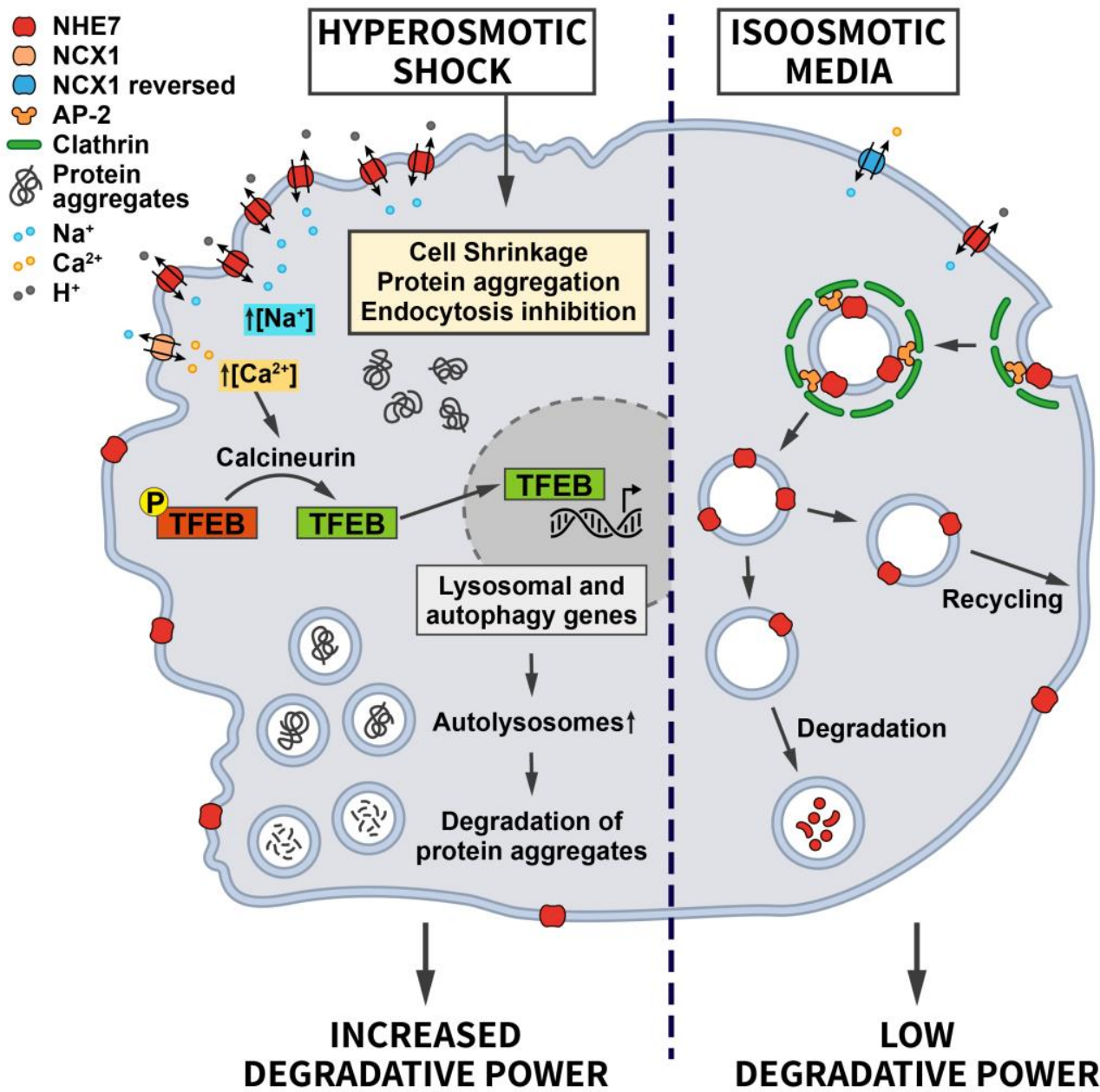

FIGURE 4: Regulation of ion transporter endocytosis by osmotic stress. Under iso-osmotic conditions NHE7 is continuously endocytosed via CME, thereby limiting its transport activity at the cell surface. Upon hyperosmotic conditions, endocytosis of NHE7 is downregulated resulting in elevated NHE7 surface levels. Increased NHE7 activity at the plasma membrane elevates $\mathrm{Na}^{+}$ influx, which via the $\mathrm{Na}^{+} / \mathrm{Ca}^{2+}$ exchanger $\mathrm{NCX} 1$ leads to increased intracellular $\mathrm{Ca}^{2+}$ levels and the $\mathrm{Ca}^{2+} /$ Calcineurin-mediated dephosphorylation of the transcription factor TFEB to induce lysosomal and autophagy gene expression. The ensuing increased cellular degradative capacity is beneficial for counteracting protein aggregation caused by hyperosmotic conditions (see section "Osmotic stress" for further details). doplasmatic reticulum downstream of ATP-activated purinergic P2YR receptors. Elevated cytosolic $\mathrm{Ca}^{2+}$ via Calmodulin induces the activation of $\mathrm{Cdc} 42$ [72], which by promoting actin polymerization may facilitate endocytosis (Figure 5). In fact, actin is known to be important for endocytosis at the apical side of polarized cells to overcome membrane tension [47]. This appears to be a very cell-type specific pathway that only operates in cells of proximal tubule origin [71].

\section{Stress due to imbalances in $\mathrm{O}_{2} / \mathrm{CO}_{2}$ supply and oxidative} species

Hypoxia $-\mathrm{O}_{2}$ stress

Hypoxia, inadequate oxygen supply, is a common stressor that cells face during fetal development, upon environmental variations such as high altitudes, and during pathological conditions like myocardial or cerebral ischemia, and in cancer (see "Oncogenic signaling") where hypoxia is very common in solid tumors [73]. Hypoxic conditions lead to the stabilization of the transcription factor HIF, which drives a transcriptional stress response for the adaptation to oxygen deprivation. Interestingly, the HIF system is also activated by oncogenes and tumor suppressor mutations [74]. In addition to triggering the HIF-mediated signaling pathway, it has been suggested that hypoxia facilitates endocytosis, thereby altering the composition of the surface proteome. For example, hypoxia promotes the internalization of the $\mathrm{Na}^{+} / \mathrm{K}^{+}$-ATPase in lung alveolar epithelium, possibly in an attempt to reduce ATP consumption [75]. CME of the $\mathrm{Na}^{+} / \mathrm{K}^{+}$-ATPase was shown to require recognition of a $Y x x \emptyset$ motif in its $\alpha$ subunit by AP- $2 \mu$ [76] and the reactive oxygen species (ROS)-induced activation of PKC- $\zeta$, which phosphorylates both, the $\mathrm{Na}^{+} / \mathrm{K}^{+}$-ATPase and AP- $2 \mu$ to induce $\mathrm{Na}^{+} / \mathrm{K}^{+}$-ATPase internalization [75] (Figure 6). Interestingly, hypoxia-induced $\mathrm{Na}^{+} / \mathrm{K}^{+}$-ATPase internalization was shown to be HIF-independent. Hypoxia also appears to facilitate the endocytosis and degradation of the alveolar epithelial sodium channel (ENaC) [77], although the underlying mechanism is less clear in this case.

The hypoxia-induced endocytosis of the $\mathrm{Na}^{+} / \mathrm{K}^{+}$-ATPase and $\mathrm{ENaC}$ are likely a cellular adaptation for preserving energy. However, a harmful consequence is the concomitant impairment of alveolar fluid clearance, which requires $\mathrm{Na}^{+}$absorption via $\mathrm{ENaC}$ at the apical side and $\mathrm{Na}^{+}$extrusion by the $\mathrm{Na}^{+} / \mathrm{K}^{+}$ATPase at the basolateral membrane [78]. To limit the extent of the resulting alveolar edema, cells activate a pro-survival response that prevents excessive $\mathrm{Na}^{+} / \mathrm{K}^{+}$-ATPase endocytosis under severe hypoxia. Hy- 


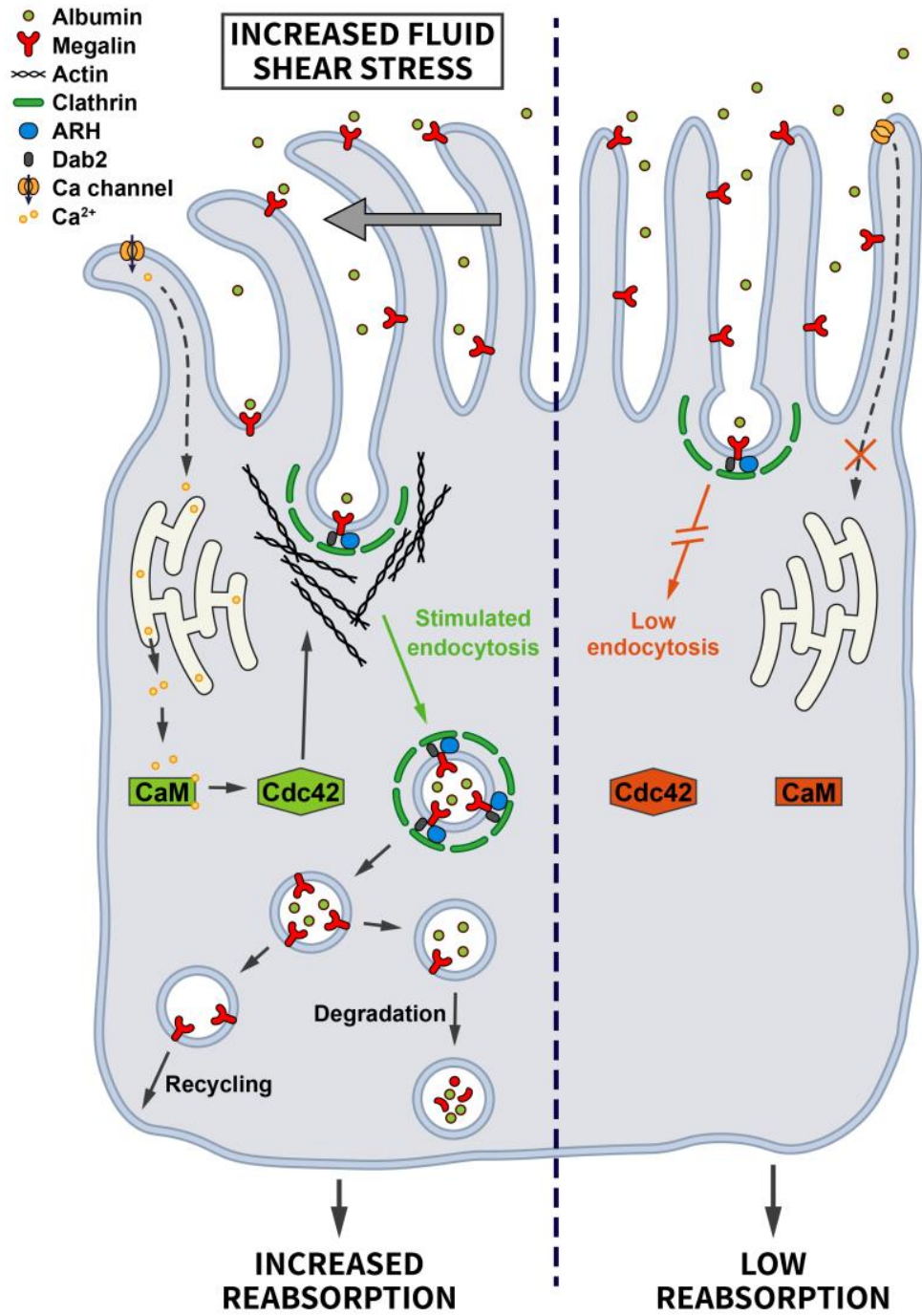

FIGURE 5: Regulation of endocytosis by mechanical stress. Proximal tubule cells are tasked with the uptake of proteins and other molecules from the glomerular filtrate. Increased fluid shear stress bends primary cilia, thereby triggering $\mathrm{Ca}^{2+}$ influx that is further amplified intracellularly. Via activation of Calmodulin this change induces Cdc42mediated actin polymerization and enhanced endocytosis to prevent proteinuria (see section "Mechanical stress" for further details). poxia-induced HIF signaling increases the levels of the E3 ubiquitin ligase HOIL-1L, which promotes the ubiquitination of PKC- $\zeta$ leading to its degradation. Consequently, PKC- $\zeta$ is prevented from further stimulating $\mathrm{Na}^{+} / \mathrm{K}^{+}$-ATPase internalization [79]. This mechanism allows cells to achieve a balance between preserving ATP and safeguarding a certain amount of alveolar fluid clearance to support survival of individual cells and the organism.

Studies in Caenorhabditis elegans suggest that neurons may modulate endocytosis in response to hypoxia. Hypoxic conditions or loss of activity of the cellular oxygen sensor EGL-9 facilitate endocytosis but impair the recycling of the glutamate receptor GLR-1 [80], leading to reduced GLR-1associated currents and behavior changes. The downregulation of surface glutamate receptors triggered by hypoxia may be considered as a neuroprotective response in order to preserve neurons from glutamate receptor-mediated excitotoxicity. Whether similar pathways operate in mammalian neurons remains to be studied. These results are consistent with the downregulation of the ionotropic glu- tamate receptors GluA2 and GluA3 in mammalian neurons under OGD (see "Glucose and energy deprivation").

EGFR signaling is also over-activated under hypoxia. Low oxygen conditions prolong the EGFR half-life in a HIFdependent manner by diminishing the rate of endosome fusion caused by reduced expression of Rab5 and its effector Rabaptin5. Rabaptin5 is normally recruited by Rab5 and stimulates the Rab5 guanine nucleotide exchange factor (GEF) Rabex5, thereby increasing Rab5 activity and early endosome fusion. Downregulation of Rabaptin5, hence, leads to a decrease of early endosome fusion and to a delay in the downstream trafficking to lysosomes and in cargo degradation [81]. Consequently, the affected receptor tyrosine kinases, which are able to signal from endosomes, display prolonged signaling responses. Prolonged receptor tyrosine kinase signaling represents an important adaptive response of the cancer cells for further oncogenesis in the hypoxic tumor environment. 


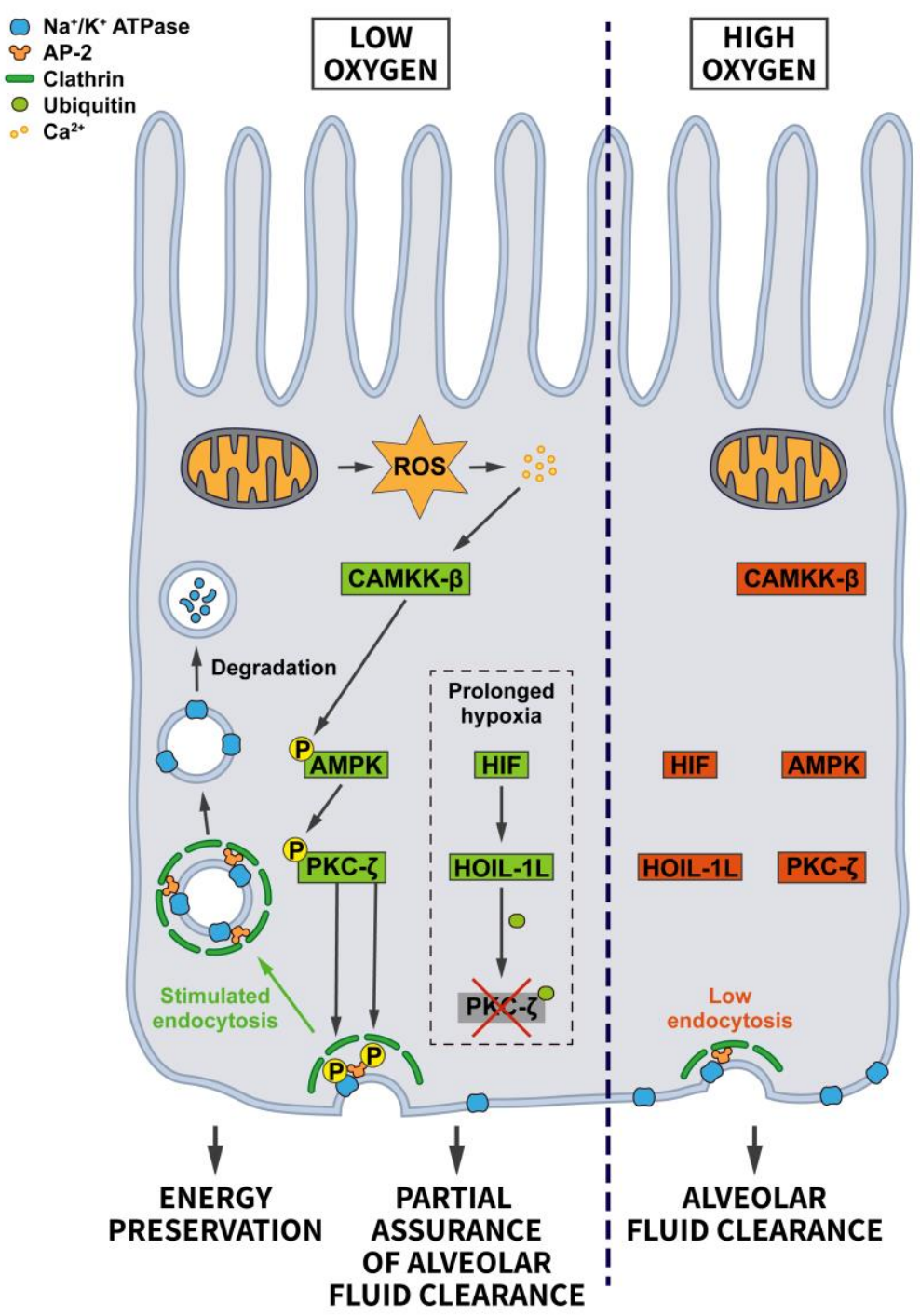

FIGURE 6: Regulation of endocytosis by oxygen stress. Under adequate oxygen supply there is limited endocytosis of the $\mathrm{Na}^{+} / \mathrm{K}^{+}$-ATPase, which is needed at the plasma membrane to build up the ion gradient that supports alveolar fluid clearance. When oxygen levels drop, the endocytosis of $\mathrm{Na}^{+} / \mathrm{K}^{+}$-ATPase is promoted to preserve energy. Hypoxia-induced ROS via an increase in $\mathrm{Ca}^{2+}$ lead to the activation of CAMKK- $\beta$ which activates AMPK and PKC- $\zeta$. PKC- $\zeta$ phosphorylates sites on AP-2 and the $\mathrm{Na}^{+} / \mathrm{K}^{+}-\mathrm{ATPase}$ to boost $\mathrm{Na}^{+} / \mathrm{K}^{+}$ ATPase endocytosis. During prolonged hypoxia, the HIF pathway triggers the ubiquitination and degradation of PKC $-\zeta$ by elevating the expression of the E3 ubiquitin ligase HOIL-1L. In this way cells balance energy preservation and alveolar fluid clearance for cellular and organismal survival (see section "Hypoxia $-\mathrm{O}_{2}$ stress" for further details).

\section{Hypercapnia - $\mathrm{CO}_{2}$ stress}

Hypercapnia is a condition in which $\mathrm{CO}_{2}$ levels in the blood are elevated, for example, due to insufficient ventilation of the alveolar epithelium, the site of gas exchange. This can occur, for example, during lung diseases such as COVID-19. Moreover, acute hypercapnic respiratory failure (AHRF) can be triggered by chronic obstructive pulmonary disease (COPD) and some forms of neuromuscular disease (e.g. myasthenia gravis and obesity hypoventilation syndrome) or any type of respiratory failure where the muscles that are needed for breathing are exhausted (e.g. severe pneumonia, acute severe asthma). To keep gas exchange optimal, alveolar epithelial cells with the help of the $\mathrm{Na}^{+} / \mathrm{K}^{+}$-ATPase and the $\mathrm{Na}^{+}$channel ENaC normally reabsorb fluid that leaks into the airspaces [78]. However, elevated $\mathrm{CO}_{2}$ levels cause a $\mathrm{Ca}^{2+}$ influx triggering a kinase cascade involving the successive activation of CaMKK- $\beta$ $\left(\mathrm{Ca}^{2+} /\right.$ Calmodulin-dependent kinase kinase- $\left.\beta\right)$, AMPK and PKC- $\zeta$ [78]. Thus, the signaling cascade converges here on the same kinase that is also induced in hypoxic alveolar epithelium and leads, among other changes, via AP-2 phosphorylation to increased uptake of $\mathrm{Na}^{+} / \mathrm{K}^{+}$-ATPase as described in section "Hypoxia $-\mathrm{O}_{2}$ stress". In addition, AMPK also triggers activation of JNK, which in turn phosphorylates the scaffolding protein Lim domain-only $7 \mathrm{~b}$ (LMO7b). Phosphorylated LMO7b on the one hand shows enhanced colocalization with the $\mathrm{Na}^{+} / \mathrm{K}^{+}$-ATPase, and on the other hand may interact with AP- $2 \mu$, thereby possibly promoting the endocytosis of the $\mathrm{Na}^{+} / \mathrm{K}^{+}$-ATPase [82].

Another critical alveolar protein whose endocytosis is upregulated upon hypercapnia is $\mathrm{ENaC} . \mathrm{CO}_{2}$ was shown to induce the ERK1/2-mediated phosphorylation of the $\beta$-subunit of ENaC. In addition, ERK1/2 causes the activation of AMPK and JNK1/2, which, in turn, phosphorylate and activate Nedd4-2. These phosphorylations lead to the Nedd4-2-dependent polyubiquitination of the $\beta$-subunit of $\mathrm{ENaC}$, thereby triggering $\mathrm{CME}$ of the $\mathrm{ENaC}$ complex [83].

Akin to hypoxia, the drawback of the lack of $\mathrm{Na}^{+} / \mathrm{K}^{+}-$ ATPase and ENaC activities under hypercapnia is the impaired alveolar fluid reabsorption that further aggravates lung injury. Therefore, preventing the $\mathrm{CO}_{2}$-induced downregulation of $\mathrm{Na}^{+} / \mathrm{K}^{+}$-ATPase and $\mathrm{ENaC}$ might be beneficial 
in conditions of lung edema. Strikingly, hypocapnia, i.e. reduced blood $\mathrm{CO}_{2}$ levels, was found to worsen alveolar fluid reabsorption similar to hypercapnia during lung injury by promoting endocytosis of $\mathrm{Na}^{+} / \mathrm{K}^{+} \mathrm{ATPase}$ [84]. Thus, opposite levels of the same stress stimulus converge on similar effects.

\section{Oxidative stress}

Cells experience oxidative stress when the generation of ROS such as peroxides, superoxides and free radicals is higher than their elimination. Oxidative imbalance arises either by an excess of ROS accumulation or a reduction in the amount of antioxidative enzymes. If cells encounter an excess of ROS, they need to activate programs to cope with the ROS-induced harmful changes. The stress response is turned on mainly via transcriptional activation of target genes that will either enhance survival or promote cell death.

Several studies suggest that increased oxidative stress directly or indirectly causes defects in the CME of LDL [8589]. Altered endocytosis of other cargoes was also reported. For example, elevated ROS were shown to inhibit EGFR and lectin receptor endocytosis in fibroblasts, likely by preventing their ubiquitination [90]. Similarly, ROS were observed to impair the internalization of GLUT4 in cardiomyocytes [91], aquaporin 4 (AQP4), transferrin and LDL in astrocytes $[92,93]$, and of synaptic vesicle membranes in neurons [94].

Regarding the potential underlying mechanism, oxidative conditions in astrocytes were reported to lead to the downregulation of the transcription factor Sp1, which promotes the transcription of Hsc70 [93], a constitutively expressed heat shock protein and an essential cofactor for the uncoating of Clathrin-coated vesicles in CME [24]. Decreased levels of $\mathrm{Hsc70}$ are expected to reduce the availability of free Clathrin for new rounds of endocytosis, since it would be sequestered in uncoating-deficient Clathrincoated vesicles or Clathrin cages [93]. However, it is unclear whether this mechanism extends to other cell types and conditions.

On the other hand, oxidative conditions have been suggested to enhance the endocytosis of apically-located transporters in liver cells. These include the multidrug resistance-associated protein 2 (Mrp2) and the bile salt export pump (Bsep) [95-97], a protein important for canalicular bile secretion. A disorganization of the actin cytoskeleton appears to be the reason for the elevated endocytosis of Mrp2 and Bsep, most likely as a consequence of ROSinduced altered $\mathrm{Ca}^{2+}$ homeostasis and PKC activation. Importantly, exogenous application of bilirubin, known for its antioxidant properties, rescues the ROS-induced changes in actin disruption and Mrp2 and Bsep downregulation [97], thereby counteracting the hepatocanalicular dysfunction associated with oxidative stress. A recent study also shows similar results for Rifampicin, an antibiotic commonly used to treat tuberculosis, but with detrimental side effects like hepatotoxicity. Rifampicin leads to increased Mrp2 endocytosis by causing oxidative stress and by activating PKCERK/JNK/p38 and PI3K signaling pathways. Interestingly, the Rifampicin-induced elevation in Mrp2 endocytosis might also be due to transcriptional/protein upregulation of Clathrin and AP-2, changes that are suppressed by antioxidants [98].

Clearly, further studies are needed to examine the effects of ROS on endocytosis and the underlying molecular mechanisms.

Stress caused by exposure to metals: Iron, platinum, and heavy metals

Iron

Endocytosis is the main route for cellular iron uptake, which is a crucial cofactor of cellular enzymes including those required for mitochondrial oxidative phosphorylation [99]. Its uptake is also associated with an increased generation of ROS, explaining why iron trafficking and metabolism must be exquisitely regulated. Iron homeostasis is under control of iron regulatory proteins (IRPs) that transcriptionally regulate the expression of target genes to maintain cellular iron metabolism such as genes encoding proteins involved in iron uptake [100].

One of the causes of iron overload is an elevated intake via intestinal absorption. In enterocytes, iron is mainly taken up by the iron $/ \mathrm{H}^{+}$cotransporter DMT1. In Caco- 2 human intestinal epithelial cells, a consequence of ROS production due to overdoses of iron is a reduced plasma membrane level of DMT1, possibly as a consequence of its ironinduced endocytosis, thereby decreasing iron uptake rates [101].

In contrast, iron deficiency leads to adaptive responses that involve an increase in the activity of iron-transporters in the small intestine as well as morphological adaptations in the intestinal mucosa such as an increase in its thickness and the length of the villi to enhance the absorption of iron by enterocytes [102]. The surface expression of transferrin receptor is also maximized in many other cell types [100].

\section{Platinum}

Platinum drugs such as Cisplatin are common standard treatments for many types of tumors. One of their side effects is nephrotoxicity. A possible mechanism underlying Cisplatin-induced proteinuria is the decreased CME of proteins in the proximal tubule and the inhibition of the vATPase [103]. Cisplatin has also been proposed to stimulate EGFR endocytosis. However, in this case EGFR does not appear to be degraded in lysosomes or recycled to the plasma membrane, but accumulates in a subpopulation of non-degradative perinuclear multivesicular bodies. In contrast to normal EGFR internalization, the Cisplatindependent EGFR endocytosis does not require ubiquitination, but is Dynamin- and AP-2 dependent. This pathway appears to be crucial for survival as AP-2 loss induces apoptosis of Cisplatin-treated cells [104].

\section{Heavy metals}

Prolonged exposure to heavy metals such as cadmium, arsenic, mercury and lead is known to induce deleterious health effects, since they can bind to proteins and replace the original metals causing protein malfunctioning. At the 
cellular level, several studies have indicated oxidative stress leading to apoptosis as a common mechanism underlying their toxicity [105]. As metal ions can enter into the cell via endocytosis complexed to chelating proteins such as metallothioneins, it is easy to conceive that decreasing endocytic rates can be considered as a protective mechanism to avoid metal-induced toxicity. In agreement, several studies have reported a downregulation of endocytosis in proximal tubule cells exposed to cadmium [106] and a reduced endocytosis/phagocytosis capacity in dendritic cells and macrophages subjected to arsenic stress [107-109]. However, downregulation of endocytosis to bypass metallotoxicity has harmful side effects such as cadmium-induced proteinuria or arsenic-induced immunosuppression.

\section{Radiation stress}

Radiotherapy is a common cancer treatment due to its contribution to cell death. It is known that penetrating radiation leads to cellular stress [110], mainly via ROS generation, protein misfolding, DNA breaks and organelle damage. However, radiotherapy has limitations due to cytotoxic effects on healthy cells and the associated radioresistance. Several papers have shown a differential impact of radiation on endocytosis. For example, defects in the migratory capacity of Langerhans cell-like dendritic cells subjected to ultraviolet $B$ radiation was related to reduced receptor-mediated and fluid-phase endocytosis [111]. In contrast, work by [112] suggests that albumin uptake and fluid-phase endocytosis remain normal in irradiated inmature and mature dendritic cells. Carbon ion irradiation is also used as cancer therapy, being considered more effective than photon irradiation. This type of radiation was shown to promote apoptosis in both immature and mature dendritic cells, in part due to impaired endocytosis [113]. Like other types of stress, e.g. cisplatin, irradiation also promotes ligand-independent endocytosis of EGFR [114, 115] via an unknown mechanism.

\section{OUTLOOK}

Beyond the examples provided here, there is little systematic knowledge about (i) which specific alterations in endocytosis are triggered by different stress conditions, (ii) how stress triggers changes in the overall endocytic capacity, (iii) which changes in the endocytic sorting of individual proteins are induced by stress, and (iv) how those changes contribute to a successful cellular adaptation to stress. Clearly, more systematic and unbiased approaches are needed to compare the effects of different stressors on endocytic flux in general and on specific endocytic cargo proteins.

In addition, it is increasingly being recognized that stress responses are not confined to individual cells. To coordinate adaptive responses within the organism, stressed cells communicate their status to their environment, either by displaying specific proteins on their surface or by releasing signal factors [116], e.g. with the help of surface-localized transport proteins. These aspects of the stress response could be supported by alterations in endocytosis. However, so far this possibility has not been investigated.

Our lack of understanding of the adaptation of endocytosis under stress conditions goes hand in hand with our limited knowledge about endocytic regulation in other physiological conditions. Even though numerous kinase pathways have been implicated in the regulation of endocytosis $[27,117]$ including some recent additions like the NIMA family kinases in C. elegans [118], how different signal transduction cascades modulate specific endocytic factors and cargo sorting in most cases has remained enigmatic. In addition to phosphorylation, ubiquitination events play a critical role in regulating the uptake of specific cargo proteins. Moreover, recent data suggest that both endocytosed cargo proteins and endocytic factors such as AP180 and AAK1 (reviewed in [119]) can also be subject to modification by carbohydrates such as O-GIcNAc that may regulate endocytosis by so far unknown mechanisms. Aside from these post-translational mechanisms, the regulation of endocytosis at the transcriptional level including the possible role of alternative splicing is only now starting to be appreciated. With advanced mass spectrometry and RNAseq-based approaches that allow to study different posttranslational modifications as well as mRNA abundance and splicing, it should become feasible to map the transcriptional and posttranslational regulation of cargo proteins and their associated endocytic factors upon different stress conditions and to delineate the underlying signaling pathways. This will pave the way for a more detailed understanding of how endocytosis is employed by mammalian cells to promote survival under stress.

\section{ACKNOWLEDGMENTS}

Work in the authors' laboratories is supported by the Deutsche Forschungsgemeinschaft (DFG, German Research Foundation) under Germany's Excellence Strategy (EXC2049-390688087) and grants to V.H. (HA2686/13-1; Reinhart-Koselleck-Award) and T.M. (MA4735/1-2; MA4735/21; MA4735/3-1). We thank Dr. Barth Rossum for his contribution to the illustrations.

\section{CONFLICT OF INTEREST}

The authors declare no conflicts of interest.

\section{COPYRIGHT}

(C) 2020 López-Hernández et al. This is an open-access article released under the terms of the Creative Commons Attribution (CC BY) license, which allows the unrestricted use, distribution, and reproduction in any medium, provided the original author and source are acknowledged.

Please cite this article as: Tania López-Hernández Volker Haucke and Tanja Maritzen (2020). Endocytosis in the adaptation to cellular stress. Cell Stress 4(10): 230-247. doi: $10.15698 /$ cst2020.10.232 


\section{REFERENCES}

1. Velichko AK, Markova EN, Petrova NV, Razin SV, Kantidze OL (2013). Mechanisms of heat shock response in mammals. Cell Mol Life Sci 70(22): 4229-4241. doi: 10.1007/s00018-013-1348-7

2. Kaksonen M, Roux A (2018). Mechanisms of clathrin-mediated endocytosis. Nat Rev Mol Cell Biol 19(5): 313-326. doi 10.1038/nrm.2017.132

3. Bitsikas V, Correa IR, Jr., Nichols BJ (2014). Clathrin-independent pathways do not contribute significantly to endocytic flux. Elife 3 : e03970. doi: 10.7554/eLife.03970

4. Traub LM, Bonifacino JS (2013). Cargo recognition in clathrinmediated endocytosis. Cold Spring Harb Perspect Biol 5(11): a016790. doi: 10.1101/cshperspect.a016790

5. Mishra SK, Watkins SC, Traub LM (2002). The autosomal recessive hypercholesterolemia (ARH) protein interfaces directly with the clathrin-coat machinery. Proc Natl Acad Sci U S A 99(25): 1609916104. doi: $10.1073 /$ pnas.252630799

6. Azarnia Tehran D, Lopez-Hernandez T, Maritzen T (2019). Endocytic Adaptor Proteins in Health and Disease: Lessons from Mode Organisms and Human Mutations. Cells 8(11): 1345. doi: 10.3390/cells8111345

7. Koo SJ, Kochlamazashvili G, Rost B, Puchkov D, Gimber N, Lehmann M, Tadeus G, Schmoranzer J, Rosenmund C, Haucke V, Maritzen T (2015). Vesicular Synaptobrevin/VAMP2 Levels Guarded by AP180 Control Efficient Neurotransmission. Neuron 88(2): 330-344. doi: 10.1016/j.neuron.2015.08.034

8. Miller SE, Sahlender DA, Graham SC, Honing S, Robinson MS, Peden AA, Owen DJ (2011). The molecular basis for the endocytosis of smal R-SNAREs by the clathrin adaptor CALM. Cell 147(5): 1118-1131. doi: 10.1016/j.cell.2011.10.038

9. Kelly BT, McCoy AJ, Spate K, Miller SE, Evans PR, Honing S, Owen DJ (2008). A structural explanation for the binding of endocytic dileucine motifs by the AP2 complex. Nature 456(7224): 976-979. doi: $10.1038 /$ nature 07422

10. Letourneur F, Klausner RD (1992). A novel di-leucine motif and a tyrosine-based motif independently mediate lysosomal targeting and endocytosis of CD3 chains. Cell 69(7): 1143-1157. doi: 10.1016/00928674(92)90636-q

11. Pond L, Kuhn LA, Teyton L, Schutze MP, Tainer JA, Jackson MR, Peterson PA (1995). A role for acidic residues in di-leucine motif-based targeting to the endocytic pathway. J Biol Chem 270(34): 1998919997. doi: $10.1074 / j b c .270 .34 .19989$

12. Haucke V, De Camilli P (1999). AP-2 recruitment to synaptotagmin stimulated by tyrosine-based endocytic motifs. Science 285(5431): 1268-1271. doi: 10.1126/science.285.5431.1268

13. Jung $N$, Wienisch $M$, Gu M, Rand JB, Muller SL, Krause $G$, Jorgensen EM, Klingauf J, Haucke V (2007). Molecular basis of synaptic vesicle cargo recognition by the endocytic sorting adaptor stonin 2 . J Cell Biol 179(7): 1497-1510. doi: 10.1083/jcb.200708107

14. Lee SE, Jeong S, Lee U, Chang SH (2019). SGIP1 functions as a selective endocytic adaptor for the internalization of synaptotagmin 1 at synapses. Mol Brain 12(1): 41. doi: 10.1186/s13041-019-0464-1

15. Beacham GM, Partlow EA, Hollopeter G (2019). Conformational regulation of AP1 and AP2 clathrin adaptor complexes. Traffic 20(10): 741-751. doi: 10.1111/tra.12677

16. Kelly BT, Graham SC, Liska N, Dannhauser PN, Honing S, Ungewickell EJ, Owen DJ (2014). Clathrin adaptors. AP2 controls clathrin polymerization with a membrane-activated switch. Science 345(6195): 459-463. doi: 10.1126/science.1254836
17. Lehmann M LI, Noé F, Schmoranzer J, Clementi C, Loerke D, Haucke V (2019). Nanoscale Coupling of Endocytic Pit Growth and Stability. Sci Adv 5(11). doi: 10.1126/sciadv.aax5775.

18. Conner SD, Schmid SL (2002). Identification of an adaptorassociated kinase, AAK1, as a regulator of clathrin-mediated endocytosis. J Cell Biol 156(5): 921-929. doi: 10.1083/jcb.200108123

19. Ricotta D, Conner SD, Schmid SL, von Figura K, Honing S (2002). Phosphorylation of the AP2 mu subunit by AAK1 mediates high affinity binding to membrane protein sorting signals. J Cell Biol 156(5): 791795. doi: $10.1083 / j c b .200111068$

20. Partlow EA, Baker RW, Beacham GM, Chappie JS, Leschziner AE, Hollopeter $G$ (2019). A structural mechanism for phosphorylationdependent inactivation of the AP2 complex. Elife 8: e50003. doi: 10.7554/eLife. 50003

21. Wrobel AG, Kadlecova Z, Kamenicky J, Yang JC, Herrmann T, Kelly BT, McCoy AJ, Evans PR, Martin S, Muller S, Salomon S, Sroubek F Neuhaus D, Honing S, Owen DJ (2019). Temporal Ordering in Endocytic Clathrin-Coated Vesicle Formation via AP2 Phosphorylation. Dev Cell 50(4): 494-508 e411. doi: 10.1016/j.devcel.2019.07.017

22. Chen Z, Krmar RT, Dada L, Efendiev R, Leibiger IB, Pedemonte $\mathrm{CH}_{\text {, }}$ Katz Al, Sznajder JI, Bertorello AM (2006). Phosphorylation of adaptor protein-2 mu2 is essential for $\mathrm{Na}+\mathrm{K}+-\mathrm{ATP}$ ase endocytosis in response to either $\mathrm{G}$ protein-coupled receptor or reactive oxygen species. Am Respir Cell Mol Biol 35(1): 127-132. doi: 10.1165/rcmb.2006-0044OC

23. Antonny B, Burd C, De Camilli $P$, Chen E, Daumke O, Faelber K, Ford M, Frolov VA, Frost A, Hinshaw JE, Kirchhausen T, Kozlov MM, Lenz $M$, Low $\mathrm{HH}$, McMahon $\mathrm{H}$, Merrifield $\mathrm{C}$, Pollard TD, Robinson PJ, Roux A, Schmid S (2016). Membrane fission by dynamin: what we know and what we need to know. Embo J 35(21): 2270-2284. doi: 10.15252/embj.201694613

24. Ungewickell E (1985). The 70-kd mammalian heat shock protein are structurally and functionally related to the uncoating protein that releases clathrin triskelia from coated vesicles. Embo J 4(13A): 3385 3391. doi: 10.1002/j.1460-2075.1985.tb04094.x

25. Almeida-Souza L, Frank RAW, Garcia-Nafria J, Colussi A, Gunawardana N, Johnson CM, Yu M, Howard G, Andrews B, Vallis Y, McMahon HT (2018). A Flat BAR Protein Promotes Actin Polymerization at the Base of Clathrin-Coated Pits. Cell 174(2): 325 337 e314. doi: 10.1016/j.cell.2018.05.020

26. Schmid SL (2017). Reciprocal regulation of signaling and endocytosis: Implications for the evolving cancer cell. J Cell Biol 216(9): 2623-2632. doi: 10.1083/jcb.201705017

27. Xiao GY, Mohanakrishnan A, Schmid SL (2018). Role for ERK1/2 dependent activation of FCHSD2 in cancer cell-selective regulation of clathrin-mediated endocytosis. Proc Natl Acad Sci U S A 115(41): E9570-E9579. doi: 10.1073/pnas.1810209115

28. McLauchlan H, Newell J, Morrice N, Osborne A, West M, Smythe E (1998). A novel role for Rab5-GDI in ligand sequestration into clathrin coated pits. Curr Biol 8(1): 34-45. doi: 10.1016/s0960-9822(98)700181

29. Bucci C, Parton RG, Mather IH, Stunnenberg H, Simons K, Hoflack $B$, Zerial M (1992). The small GTPase rab5 functions as a regulatory factor in the early endocytic pathway. Cell 70(5): 715-728. doi: 10.1016/0092-8674(92)90306-w

30. Zeigerer A, Gilleron J, Bogorad RL, Marsico G, Nonaka H, Seifert S, Epstein-Barash H, Kuchimanchi S, Peng CG, Ruda VM, Del Conte-Zerial $P$, Hengstler JG, Kalaidzidis $Y$, Koteliansky V, Zerial M (2012). Rab5 is necessary for the biogenesis of the endolysosomal system in vivo. Nature 485(7399): 465-470. doi: 10.1038/nature11133 
31. Aisen P, Listowsky I (1980). Iron transport and storage proteins. Annu Rev Biochem 49(357-393. doi: 10.1146/annurev.bi.49.070180.002041

32. Zhao Z, Pompey S, Dong H, Weng J, Garuti R, Michaely P (2013). Snitrosylation of $A R H$ is required for LDL uptake by the LDL receptor. J Lipid Res 54(6): 1550-1559. doi: 10.1194/jlr.M033167

33. Cavalli V, Vilbois F, Corti M, Marcote MJ, Tamura K, Karin M, Arkinstall S, Gruenberg J (2001). The stress-induced MAP kinase p38 regulates endocytic trafficking via the GDI:Rab5 complex. Mol Cell 7(2): 421-432. doi: 10.1016/s1097-2765(01)00189-7

34. Han Y, Cui J, Lu Y, Sue S, Arpaia E, Mak TW, Minden MD (2012). FCHSD2 predicts response to chemotherapy in acute myeloid leukemia patients. Leuk Res 36(11): 1339-1346. doi 10.1016/j.leukres.2012.06.011

35. MacGurn JA, Hsu PC, Smolka MB, Emr SD (2011). TORC1 regulates endocytosis via Npr1-mediated phosphoinhibition of a ubiquitin ligase adaptor. Cell 147(5): 1104-1117. doi: 10.1016/j.cell.2011.09.054

36. Puca L, Brou C (2014). Alpha-arrestins - new players in Notch and GPCR signaling pathways in mammals. J Cell Sci 127(Pt 7): 1359-1367. doi: $10.1242 /$ jcs.142539

37. Ling NXY, Kaczmarek A, Hoque A, Davie E, Ngoei KRW, Morrison KR, Smiles WJ, Forte GM, Wang T, Lie S, Dite TA, Langendorf CG, Scott JW, Oakhill JS, Petersen J (2020). mTORC1 directly inhibits AMPK to promote cell proliferation under nutrient stress. Nat Metab 2(1): 41 49. doi: 10.1038/s42255-019-0157-1

38. Mejlvang J, Olsvik $H$, Svenning $S$, Bruun JA, Abudu YP, Larsen KB, Brech $A$, Hansen TE, Brenne $H$, Hansen $T$, Stenmark $H$, Johansen $T$ (2018). Starvation induces rapid degradation of selective autophagy receptors by endosomal microautophagy. J Cell Biol 217(10): 36403655. doi: $10.1083 / j \mathrm{cb} .201711002$

39. Wu N, Zheng B, Shaywitz A, Dagon Y, Tower C, Bellinger G, Shen $\mathrm{CH}$, Wen J, Asara J, McGraw TE, Kahn BB, Cantley LC (2013). AMPKdependent degradation of TXNIP upon energy stress leads to enhanced glucose uptake via GLUT1. Mol Cell 49(6): 1167-1175. doi: 10.1016/j.molcel.2013.01.035

40. Lang MJ, Martinez-Marquez JY, Prosser DC, Ganser LR, Buelto D, Wendland B, Duncan MC (2014). Glucose starvation inhibits autophagy via vacuolar hydrolysis and induces plasma membrane internalization by down-regulating recycling. J Biol Chem 289(24): 16736-16747. doi: 10.1074/jbc.M113.525782

41. Koszegi Z, Fiuza M, Hanley JG (2017). Endocytosis and lysosomal degradation of GluA2/3 AMPARs in response to oxygen/glucose deprivation in hippocampal but not cortical neurons. Sci Rep-Uk 7(1):12318. doi: 10.1038/s41598-017-12534-w

42. Smith KR, Muir J, Rao Y, Browarski M, Gruenig MC, Sheehan DF, Haucke V, Kittler JT (2012). Stabilization of $\operatorname{GABA}(A)$ receptors at endocytic zones is mediated by an AP2 binding motif within the GABA(A) receptor beta3 subunit. J Neurosci 32(7): 2485-2498. doi: 10.1523/JNEUROSCI.1622-11.2011

43. Alfieri RR, Petronini PG (2007). Hyperosmotic stress response: comparison with other cellular stresses. Pflugers Arch 454(2): 173 185. doi: 10.1007/s00424-006-0195-x

44. Madshus IH, Sandvig K, Olsnes S, van Deurs B (1987). Effect of reduced endocytosis induced by hypotonic shock and potassium depletion on the infection of Hep 2 cells by picornaviruses. J Cell Physiol 131(1): 14-22. doi: 10.1002/jcp.1041310104

45. Rauch C, Farge E (2000). Endocytosis switch controlled by transmembrane osmotic pressure and phospholipid number asymmetry. Biophys J 78(6): 3036-3047. doi: 10.1016/S00063495(00)76842-1
46. Bayer N, Schober D, Huttinger M, Blaas D, Fuchs R (2001). Inhibition of clathrin-dependent endocytosis has multiple effects on human rhinovirus serotype 2 cell entry. J Biol Chem 276(6): 3952 3962. doi: 10.1074/jbc.M004722200

47. Boulant S, Kural C, Zeeh JC, Ubelmann F, Kirchhausen T (2011). Actin dynamics counteract membrane tension during clathrinmediated endocytosis. Nat Cell Biol 13(9): 1124-1131. doi: $10.1038 /$ ncb2307

48. Daukas G, Zigmond SH (1985). Inhibition of receptor-mediated but not fluid-phase endocytosis in polymorphonuclear leukocytes. J Cell Biol 101(5 Pt 1): 1673-1679. doi: 10.1083/jcb.101.5.1673

49. Heuser J (1989). Effects of cytoplasmic acidification on clathrin lattice morphology. J Cell Biol 108(2): 401-411. doi 10.1083/jcb.108.2.401

50. Pintsch T, Satre M, Klein G, Martin JB, Schuster SC (2001). Cytosolic acidification as a signal mediating hyperosmotic stress responses in Dictyostelium discoideum. BMC Cell Biol 2: 9. doi: 10.1186/14712121-2-9

51. Wang S, Singh RD, Godin L, Pagano RE, Hubmayr RD (2011). Endocytic response of type I alveolar epithelial cells to hypertonic stress. Am J Physiol Lung Cell Mol Physiol 300(4): L560-568. doi: 10.1152/ajplung.00309.2010

52. Blot V, McGraw TE (2006). GLUT4 is internalized by a cholesteroldependent nystatin-sensitive mechanism inhibited by insulin. Embo J 25(24): 5648-5658. doi: 10.1038/sj.emboj.7601462

53. Li D, Randhawa VK, Patel N, Hayashi M, Klip A (2001). Hyperosmolarity reduces GLUT4 endocytosis and increases its exocytosis from a VAMP2-independent pool in 16 muscle cells. J Biol Chem 276(25): 22883-22891. doi: 10.1074/jbc.M010143200

54. Hasler U, Nunes P, Bouley R, Lu HA, Matsuzaki T, Brown D (2008). Acute hypertonicity alters aquaporin-2 trafficking and induces a MAPK-dependent accumulation at the plasma membrane of renal epithelial cells. J Biol Chem 283(39): 26643-26661. doi: 10.1074/jbc.M801071200

55. López-Hernández T PD, Krause E, Maritzen T, Haucke V (2020). Endocytic regulation of cellular ion homeostasis controls lysosome biogenesis. Nat Cell Biol 22(7):815-827. doi: 10.1038/s41556-0200535-7

56. Nunes $P$, Ernandez T, Roth I, Qiao X, Strebel D, Bouley R, Charollais A, Ramadori P, Foti M, Meda P, Feraille E, Brown D, Hasler U (2013). Hypertonic stress promotes autophagy and microtubule-dependent autophagosomal clusters. Autophagy 9(4): 550-567. doi: 10.4161/auto. 23662

57. Tamura N, Kageyama S, Komatsu M, Waguri S (2019) Hyperosmotic Stress Induces Unconventional Autophagy Independent of the Ulk1 Complex. Mol Cell Biol 39(16): e00024-19. doi: 10.1128/MCB.00024-19

58. Bonangelino CJ, Nau JJ, Duex JE, Brinkman M, Wurmser AE, Gary JD, Emr SD, Weisman LS (2002). Osmotic stress-induced increase of phosphatidylinositol 3,5-bisphosphate requires Vac14p, an activator of the lipid kinase Fab1p. J Cell Biol 156(6): 1015-1028. doi: 10.1083/jcb.200201002

59. Jin $\mathrm{N}$, Jin $\mathrm{Y}$, Weisman LS (2017). Early protection to stress mediated by CDK-dependent $\mathrm{PI}, 5 \mathrm{P} 2$ signaling from the vacuole/lysosome. J Cell Biol 216(7): 2075-2090. doi: $10.1083 /$ jcb.201611144

60. Hasegawa J, Strunk BS, Weisman LS (2017). PI5P and PI(3,5)P2: Minor, but Essential Phosphoinositides. Cell Struct Funct 42(1): 49-60. doi: $10.1247 /$ csf.17003 
61. Guiney EL, Goldman AR, Elias JE, Cyert MS (2015). Calcineurin regulates the yeast synaptojanin Inp53/Sjl3 during membrane stress. Mol Biol Cell 26(4): 769-785. doi: 10.1091/mbc.E14-05-1019

62. Cheung G, Cousin MA (2013). Synaptic vesicle generation from activity-dependent bulk endosomes requires calcium and calcineurin J Neurosci 33(8): 3370-3379. doi: 10.1523/JNEUROSCI.4697-12.2013

63. Yan $Y$, Ding $Y$, Ming B, Du W, Kong $X$, Tian L, Zheng F, Fang $M$, Tan $Z$, Gong $F$ (2014). Increase in hypotonic stress-induced endocytic activity in macrophages via CIC-3. Mol Cells 37(5): 418-425. doi: 10.14348/molcells.2014.0031

64. Fujii N, Matsuo $Y$, Matsunaga T, Endo S, Sakai H, Yamaguchi M, Yamazaki Y, Sugatani J, Ikari A (2016). Hypotonic Stress-induced Down-regulation of Claudin-1 and -2 Mediated by Dephosphorylation and Clathrin-dependent Endocytosis in Renal Tubular Epithelial Cells. J Biol Chem 291(47): 24787-24799. doi: 10.1074/jbc.M116.728196

65. Kang H, Cancel LM, Tarbell JM (2014). Effect of shear stress on water and LDL transport through cultured endothelial cell monolayers. Atherosclerosis 233(2): 682-690. doi: 10.1016/j.atherosclerosis.2014.01.056

66. Niwa K, Karino T (2005). The effect of a shear flow on the uptake of LDL and Ac-LDL by cultured vascular endothelial cells. Jsme Int J CMech Sy 48(4): 436-443. doi: 10.1299/jsmec.48.436

67. Niwa K, Kado T, Sakai J, Karino T (2004). The effects of a shear flow on the uptake of LDL and acetylated LDL by an EC monoculture and an EC-SMC coculture. Ann Biomed Eng 32(4): 537-543. doi: 10.1023/b:abme.0000019173.79939.54

68. Traore M, Sun RJ, Fawzi-Grancher S, Dumas D, Qing X, Santus R, Stoltz JF, Muller S (2005). Kinetics of the endocytotic pathway of Low Density Lipoprotein (LDL) in human endothelial cells line under shear stress: an in vitro confocal microscopy study. Clin Hemorheol Microcirc 33(3): 243-251. PMID: 16215290

69. Castro-Nunez L, Dienava-Verdoold I, Herczenik E, Mertens K, Meijer AB (2012). Shear stress is required for the endocytic uptake of the factor VIII-von Willebrand factor complex by macrophages. J Thromb Haemost 10(9): 1929-1937. doi: 10.1111/j.15387836.2012.04860.x

70. Long KR, Shipman KE, Rbaibi Y, Menshikova EV, Ritov VB, Eshbach $\mathrm{ML}$, Jiang $\mathrm{Y}$, Jackson EK, Baty CJ, Weisz OA (2017). Proximal tubule apical endocytosis is modulated by fluid shear stress via an mTORdependent pathway. Mol Bio Cell 28(19): 2508-2517. doi: 10.1091/mbc.E17-04-0211

71. Raghavan V, Rbaibi Y, Pastor-Soler NM, Carattino MD, Weisz OA (2014). Shear stress-dependent regulation of apical endocytosis in renal proximal tubule cells mediated by primary cilia. Proc Natl Acad Sci U S A 111(23): 8506-8511. doi: 10.1073/pnas.1402195111

72. Bhattacharyya S, Jean-Alphonse FG, Raghavan V, McGarvey JC, Rbaibi Y, Vilardaga JP, Carattino MD, Weisz OA (2017). Cdc42 activation couples fluid shear stress to apical endocytosis in proximal tubule cells. Physiol Rep 5(19): e13460. doi: 10.14814/phy2.13460.

73. Wang Y, Ohh M (2010). Oxygen-mediated endocytosis in cancer. J Cell Mol Med 14(3): 496-503. doi: 10.1111/j.1582-4934.2010.01016.x

74. Masson N, Ratcliffe PJ (2014). Hypoxia signaling pathways in cancer metabolism: the importance of co-selecting interconnected physiological pathways. Cancer Metab 2(1): 3. doi: 10.1186/20493002-2-3

75. Dada LA, Chandel NS, Ridge KM, Pedemonte C, Bertorello AM, Sznajder Jl (2003). Hypoxia-induced endocytosis of $\mathrm{Na}, \mathrm{K}-\mathrm{ATP}$ ase in alveolar epithelial cells is mediated by mitochondrial reactive oxygen species and PKC-zeta. J Clin Invest 111(7): 1057-1064. doi: $10.1172 / \mathrm{JCl} 16826$
76. Done SC, Leibiger IB, Efendiev R, Katz Al, Leibiger B, Berggren PO, Pedemonte $\mathrm{CH}$, Bertorello AM (2002). Tyrosine 537 within the $\mathrm{Na}+, \mathrm{K}+$ ATPase alpha-subunit is essential for AP-2 binding and clathrindependent endocytosis. J Biol Chem 277(19): 17108-17111. doi: 10.1074/jbc.M201326200

77. Gille T, Randrianarison-Pellan N, Goolaerts A, Dard N, Uzunhan Y, Ferrary E, Hummler E, Clerici C, Planes C (2014). Hypoxia-Induced Inhibition of Epithelial Na+ Channels in the Lung Role of Nedd4-2 and the Ubiquitin-Proteasome Pathway. Am J Resp Cell Mol 50(3): 526537. doi: 10.1165/rcmb.2012-05180C

78. Vadasz I, Dada LA, Briva A, Trejo HE, Welch LC, Chen J, Toth PT, Lecuona E, Witters LA, Schumacker PT, Chandel NS, Seeger W, Sznajder JI (2008). AMP-activated protein kinase regulates $\mathrm{CO} 2$ induced alveolar epithelial dysfunction in rats and human cells by promoting $\mathrm{Na}$,K-ATPase endocytosis. J Clin Invest 118(2): 752-762. doi: $10.1172 / \mathrm{JCl} 29723$

79. Magnani ND, Dada LA, Queisser MA, Brazee PL, Welch LC, Anekalla KR, Zhou G, Vagin O, Misharin AV, Budinger GRS, Iwai K, Ciechanover AJ, Sznajder JI (2017). HIF and HOIL-1L-mediated PKCzeta degradation stabilizes plasma membrane $\mathrm{Na}, \mathrm{K}$-ATPase to protect against hypoxiainduced lung injury. Proc Natl Acad Sci U S A 114(47): E10178-E10186. doi: 10.1073/pnas.1713563114

80. Park EC, Ghose P, Shao ZY, Ye Q, Kang L, Xu XZS, Powell-Coffman $J A$, Rongo C (2012). Hypoxia regulates glutamate receptor trafficking through an HIF-independent mechanism (vol 31, pg 1379, 2012). Embo Journal 31(6): 1618-1619. doi: 10.1038/emboj.2012.44

81. Wang $Y$, Roche $O$, Yan MS, Finak G, Evans AJ, Metcalf JL, Hast BE, Hanna SC, Wondergem B, Furge KA, Irwin MS, Kim WY, Teh BT, Grinstein S, Park M, Marsden PA, Ohh M (2009). Regulation of endocytosis via the oxygen-sensing pathway. Nat Med 15(3): 319-324. doi: $10.1038 / \mathrm{nm} .1922$

82. Dada LA, Trejo Bittar HE, Welch LC, Vagin O, Deiss-Yehiely N, Kelly AM, Baker MR, Capri J, Cohn W, Whitelegge JP, Vadasz I, Gruenbaum Y, Sznajder JI (2015). High CO2 Leads to Na,K-ATPase Endocytosis via c-Jun Amino-Terminal Kinase-Induced LMO7b Phosphorylation. Mol Cell Biol 35(23): 3962-3973. doi: 10.1128/MCB.00813-15

83. Gwozdzinska P, Buchbinder BA, Mayer K, Herold S, Morty RE, Seeger W, Vadasz I (2017). Hypercapnia Impairs ENaC Cell Surface Stability by Promoting Phosphorylation, Polyubiquitination and Endocytosis of beta-ENaC in a Human Alveolar Epithelial Cell Line. Front Immunol 8: 591. doi: 10.3389/fimmu.2017.00591

84. Myrianthefs PM, Briva A, Lecuona E, Dumasius V, Rutschman DH, Ridge KM, Baltopoulos GJ, Sznajder JI (2005). Hypocapnic but not metabolic alkalosis impairs alveolar fluid reabsorption. Am J Respir Crit Care Med 171(11): 1267-1271. doi: 10.1164/rccm.200408-9980C

85. Thibaut-Vercruyssen R, Poumay $Y$, Ronveaux-Dupal MF (1992). Influence of a short oxidative stress on the LDL endocytosis by human endothelial cells: an ultrastructural study. J Submicrosc Cytol Pathol 24(1): 61-73. PMID: 1617613

86. Aguilar-Gaytan R, Mas-Oliva J (2003). Oxidative stress impairs endocytosis of the scavenger receptor class A. Biochem Biophys Res Commun 305(3): 510-517. doi: 10.1016/s0006-291x(03)00796-4

87. Malorni W, losi F, Santini MT, Testa U (1993). Menadione-induced oxidative stress leads to a rapid down-modulation of transferrin receptor recycling. J Cell Sci 106 ( Pt 1): 309-318. PMID: 8270633

88. Cheng J, Vieira A (2006). Oxidative stress disrupts internalization and endocytic trafficking of transferrin in a human malignant keratinocyte line. Cell Biochem Biophys 45(2): 177-184. doi: Doi 10.1385/Cbb:45:2:177

89. Parry SN, Ellis N, Li Z, Maitz P, Witting PK (2008). Myoglobin induces oxidative stress and decreases endocytosis and monolayer 
permissiveness in cultured kidney epithelial cells without affecting viability. Kidney Blood Press R 31(1): 16-28. doi: 10.1159/000112921

90. De Wit R, Makkinje M, Boonstra J, Verkleij AJ, Post JA (2001). Hydrogen peroxide reversibly inhibits epidermal growth factor (EGF) receptor internalization and coincident ubiquitination of the EGF receptor and Eps15. Faseb J 15(2): 306-308. doi: 10.1096/fj.00-0454fje

91. Yang J, Holman GD (2005). Insulin and contraction stimulate exocytosis, but increased AMP-activated protein kinase activity resulting from oxidative metabolism stress slows endocytosis of GLUT4 in cardiomyocytes. J Biol Chem 280(6): 4070-4078. doi: 10.1074/jbc.M410213200

92. Bi CS, Tham DKL, Perronnet C, Joshi B, Nabi IR, Moukhles H (2017). The Oxidative Stress-Induced Increase in the Membrane Expression of the Water-Permeable Channel Aquaporin-4 in Astrocytes Is Regulated by Caveolin-1 Phosphorylation. Front Cell Neurosci 11: 412. doi: 10.3389/fncel.2017.00412

93. Volpert G, Ben-Dor S, Tarcic O, Duan J, Saada A, Merrill AH, Jr., Pewzner-Jung $Y$, Futerman $\mathrm{AH}$ (2017). Oxidative stress elicited by modifying the ceramide acyl chain length reduces the rate of clathrinmediated endocytosis. J Cell Sci 130(8): 1486-1493. doi: $10.1242 /$ jcs. 199968

94. Pereira C, Martins LM, Saraiva L (2014). LRRK2, but not pathogenic mutants, protects against $\mathrm{H} 2 \mathrm{O} 2$ stress depending on mitochondrial function and endocytosis in a yeast model. Bba-Gen Subjects 1840(6): 2025-2031. doi: 10.1016/j.bbagen.2014.02.015

95. Ji B, Ito K, Sekine S, Tajima A, Horie T (2004). Ethacrynic-acidinduced glutathione depletion and oxidative stress in normal and Mrp2-deficient rat liver. Free Radical Bio Med 37(11): 1718-1729. doi: 10.1016/j.freeradbiomed.2004.08.020

96. Sekine S, Ito K, Horie T (2008). Canalicular Mrp2 localization is reversibly regulated by the intracellular redox status. Am J PhysiolGastr L 295(5): G1035-G1041. doi: 10.1152/ajpgi.90404.2008

97. Basiglio CL, Toledo FD, Boaglio AC, Arriaga SM, Ochoa JE, Pozzi EJS, Mottino AD, Roma MG (2014). Physiological concentrations of unconjugated bilirubin prevent oxidative stress-induced hepatocanalicular dysfunction and cholestasis. Arch Toxicol 88(2): 501-514. doi: 10.1007/s00204-013-1143-0

98. Xu BY, Tang XD, Chen J, Wu HB, Chen WS, Chen L (2020). Rifampicin induces clathrin-dependent endocytosis and ubiquitinproteasome degradation of MRP2 via oxidative stress-activated PKCERK/JNK/p38 and PI3K signaling pathways in HepG2 cells. Acta Pharmacol Sin 41(1): 56-64. doi: 10.1038/s41401-019-0266-0

99. Aisen P, Listowsky I (1980). Iron Transport and Storage Proteins. Annu Rev Biochem 49: 357-393. doi: 10.1146/annurev.bi.49.070180.002041

100. Eisenstein RS, Ross KL (2003). Novel roles for iron regulatory proteins in the adaptive response to iron deficiency. J Nutr 133(5 Suppl 1): 1510S-1516S. doi: 10.1093/jn/133.5.1510S

101. Esparza A, Gerdtzen ZP, Olivera-Nappa A, Salgado JC, Nunez MT (2015). Iron-induced reactive oxygen species mediate transporter DMT1 endocytosis and iron uptake in intestinal epithelial cells. Am J Physiol Cell Physiol 309(8): C558-567. doi: 10.1152/ajpcell.00412.2014

102. Gulec S, Anderson GJ, Collins JF (2014). Mechanistic and regulatory aspects of intestinal iron absorption. Am J Physiol Gastrointest Liver Physiol 307(4): G397-409. doi: 10.1152/ajpgi.00348.2013

103. Takano M, Nakanishi N, Kitahara Y, Sasaki Y, Murakami T, Nagai J (2002). Cisplatin-induced inhibition of receptor-mediated endocytosis of protein in the kidney. Kidney Int 62(5): 1707-1717. doi: 10.1046/j.1523-1755.2002.00623.x
104. Tomas A, Vaughan SO, Burgoyne T, Sorkin A, Hartley JA, Hochhauser D, Futter CE (2015). WASH and Tsg101/ALIX-dependent diversion of stress-internalized EGFR from the canonical endocytic pathway. Nat Commun 6: 7324. doi: 10.1038/ncomms8324

105. Sabolic I (2006). Common mechanisms in nephropathy induced by toxic metals. Nephron Physiol 104(3): 107-114. doi: 10.1159/000095539

106. Herak-Kramberger CM, Brown D, Sabolic I (1998). Cadmium inhibits vacuolar $\mathrm{H}(+)$-ATPase and endocytosis in rat kidney cortex. Kidney Int 53(6): 1713-1726. doi: 10.1046/j.1523-1755.1998.00914.x

107. Lemarie A, Morzadec C, Bourdonnay E, Fardel O, Vernhet L (2006). Human macrophages constitute targets for immunotoxic inorganic arsenic. J Immunol 177(5): 3019-3027. doi: 10.4049/jimmunol.177.5.3019

108. Macoch M, Morzadec C, Fardel O, Vernhet L (2013). Inorganic arsenic impairs differentiation and functions of human dendritic cells. Toxicol Appl Pharmacol 266(2): 204-213. doi: 10.1016/j.taap.2012.11.008

109. Dangleben NL, Skibola CF, Smith MT (2013). Arsenic immunotoxicity: a review. Environ Health 12(1): 73. doi: 10.1186/1476-069X-12-73

110. Kim W, Lee S, Seo D, Kim D, Kim K, Kim E, Kang J, Seong KM, Youn H, Youn B (2019). Cellular Stress Responses in Radiotherapy. Cells 8(9): 1105. doi: 10.3390/cells8091105

111. Mizuno K, Okamoto $\mathrm{H}$, Horio $\mathrm{T}$ (2004). Ultraviolet B radiation suppresses endocytosis, subsequent maturation, and migration activity of langerhans cell-like dendritic cells. J Invest Dermato 122(2): 300-306. doi: 10.1046/j.0022-202X.2004.22206.x

112. Merrick A, Errington F, Milward K, O'Donnell D, Harrington $K$, Bateman A, Pandha H, Vile R, Morrison E, Selby P, Melcher A (2005). Immunosuppressive effects of radiation on human dendritic cells: reduced IL-12 production on activation and impairment of naive T-cell priming. Br J Cancer 92(8): 1450-1458. doi: 10.1038/sj.bjc. 6602518

113. Zhang P, Hu X, Liu B, Liu Z, Liu C, Cai J, Gao F, Cui J, Li B, Yang Y (2018). Effects of 12C6+ Heavy Ion Radiation on Dendritic Cells Function. Med Sci Monit 24: 1457-1463. doi: 10.12659/msm.906221

114. Rosette C, Karin M (1996). Ultraviolet light and osmotic stress: activation of the JNK cascade through multiple growth factor and cytokine receptors. Science 274(5290): 1194-1197. doi: $10.1126 /$ science. 274.5290 .1194

115. Peng K, Dai Q, Wei J, Shao G, Sun A, Yang W, Lin Q (2016). Stressinduced endocytosis and degradation of epidermal growth factor receptor are two independent processes. Cancer Cell Int 16: 25. doi: 10.1186/s12935-016-0301-x

116. Galluzzi L, Yamazaki T, Kroemer G (2018). Linking cellular stress responses to systemic homeostasis. Nat Rev Mol Cell Biol 19(11): 731745. doi: 10.1038/s41580-018-0068-0.

117. Liberali $P$, Ramo $P$, Pelkmans L (2008). Protein kinases: starting a molecular systems view of endocytosis. Annu Rev Cell Dev Biol 24: 501-523. doi: 10.1146/annurev.cellbio.041008.145637

118. Joseph BB, Wang Y, Edeen P, Lazetic V, Grant BD, Fay DS (2020). Control of clathrin-mediated endocytosis by NIMA family kinases. PLoS Genet 16(2): e1008633. doi: 10.1371/journal.pgen.1008633

119. Rahmani S, Defferrari MS, Wakarchuk WW, Antonescu CN (2019). Energetic adaptations: Metabolic control of endocytic membrane traffic. Traffic 20(12): 912-931. doi: 10.1111/tra.12705

120. Smith EW, Lima WC, Charette SJ, Cosson P (2010). Effect of starvation on the endocytic pathway in Dictyostelium cells. Eukaryot Cell 9(3): 387-392. doi: 10.1128/EC.00285-09 
121. Rainero E, Howe JD, Caswell PT, Jamieson NB, Anderson K, Critchley DR, Machesky L, Norman JC (2015). Ligand-Occupied Integrin Internalization Links Nutrient Signaling to Invasive Migration. Cell Rep 10(3): 398-413. doi: 10.1016/j.celrep.2014.12.037

122. Muranen T, Iwanicki MP, Curry NL, Hwang J, DuBois CD, Coloff JL, Hitchcock DS, Clish CB, Brugge JS, Kalaany NY (2017). Starved epithelial cells uptake extracellular matrix for survival. Nat Commun 8: 13989. doi: 10.1038/ncomms13989

123. Miermont A, Waharte F, Hu S, McClean MN, Bottani S, Leon S, Hersen $P$ (2013). Severe osmotic compression triggers a slowdown of intracellular signaling, which can be explained by molecular crowding.
Proc Natl Acad Sci U S A 110(14): 5725-5730. doi: $10.1073 /$ pnas. 1215367110

124. Dada LA, Chandel NS, Ridge KM, Pedemonte C, Bertorello AM, Sznajder JI (2003). Hypoxia-induced endocytosis of $\mathrm{Na}, \mathrm{K}-A T P a s e$ in alveolar epithelial cells is mediated by mitochondrial reactive oxygen species and PKC-zeta. J Clin Invest 111(7): 1057-1064. doi: 10.1172/Jci200316826

125. Gwozdzinska P, Buchbinder BA, Mayer K, Herold S, Morty RE, Seeger W, Vadasz I (2017). Hypercapnia Impairs ENaC Cell Surface Stability by Promoting Phosphorylation, Polyubiquitination and Endocytosis of beta-ENaC in a Human Alveolar Epithelial Cell Line. Front Immunol 8: 591. doi: 10.3389/fimmu.2017.00591 